\title{
Management of hyperglycaemia in type 2 diabetes, 2018. A consensus report by the American Diabetes Association (ADA) and the European Association for the Study of Diabetes (EASD)
}

\author{
Melanie J. Davies ${ }^{1,2}$ • David A. D'Alessio ${ }^{3}$. Judith Fradkin ${ }^{4}$ • Walter N. Kernan ${ }^{5}$. Chantal Mathieu ${ }^{6}$. \\ Geltrude Mingrone ${ }^{7,8} \cdot$ Peter Rossing ${ }^{9,10} \cdot$ Apostolos Tsapas $^{11} \cdot$ Deborah J. Wexler ${ }^{12,13} \cdot$ John B. Buse ${ }^{14}$
}

Published online: 5 October 2018

(C) European Association for the Study of Diabetes and American Diabetes Association 2018

\begin{abstract}
The American Diabetes Association and the European Association for the Study of Diabetes convened a panel to update the prior position statements, published in 2012 and 2015, on the management of type 2 diabetes in adults. A systematic evaluation of the literature since 2014 informed new recommendations. These include additional focus on lifestyle management and diabetes selfmanagement education and support. For those with obesity, efforts targeting weight loss, including lifestyle, medication and surgical interventions, are recommended. With regards to medication management, for patients with clinical cardiovascular disease, a sodiumglucose cotransporter-2 (SGLT2) inhibitor or a glucagon-like peptide-1 (GLP-1) receptor agonist with proven cardiovascular benefit is recommended. For patients with chronic kidney disease or clinical heart failure and atherosclerotic cardiovascular disease, an SGLT2 inhibitor with proven benefit is recommended. GLP-1 receptor agonists are generally recommended as the first injectable medication.
\end{abstract}

Keywords Cardiovascular disease $\cdot$ Chronic kidney disease $\cdot$ Costs $\cdot$ Glucose-lowering therapy $\cdot$ Guidelines $\cdot$ Heart failure Hypoglycaemia $\cdot$ Patient-centred care $\cdot$ Type 2 diabetes mellitus $\cdot$ Weight management

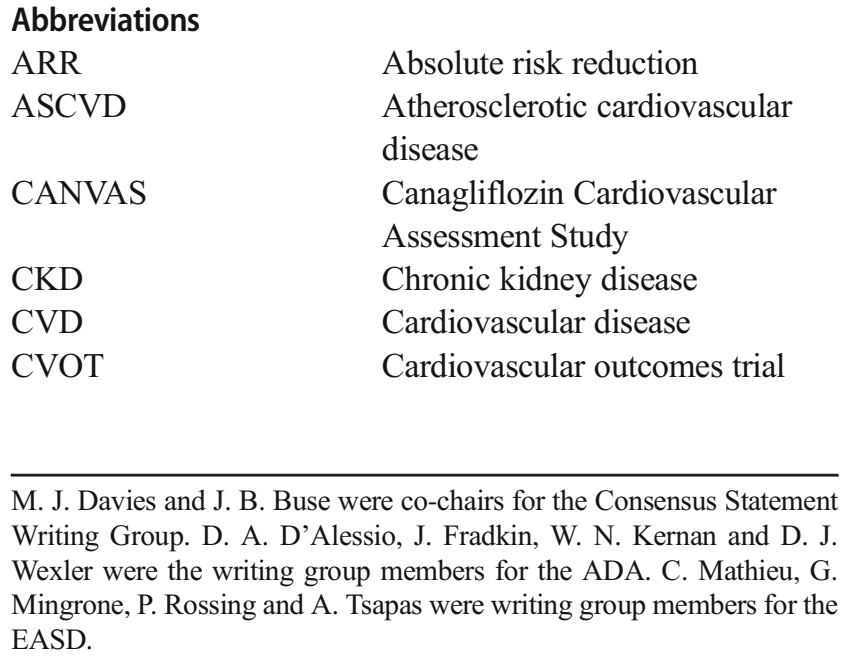

This article is being simultaneously published in Diabetes Care and Diabetologia by the American Diabetes Association and the European Association for the Study of Diabetes.

Melanie J. Davies

Melanie.davies@uhl-tr.nhs.uk

Extended author information available on the last page of the article

$\begin{array}{ll}\text { DKA } & \text { Diabetic ketoacidosis } \\ \text { DPP-4 } & \text { Dipeptidyl peptidase-4 } \\ \text { DPP-4i } & \text { Dipeptidyl peptidase-4 inhibitor } \\ \text { DSMES } & \begin{array}{l}\text { Diabetes self-management } \\ \text { education and support }\end{array} \\ \text { EMPA-REG OUTCOME } & \begin{array}{l}\text { Empagliflozin, Cardiovascular } \\ \text { Outcome Event Trial in Type 2 }\end{array} \\ & \text { Diabetes Mellitus Patients } \\ \text { ESRD } & \text { End-stage renal disease } \\ \text { EXSCEL } & \text { Exenatide Study of } \\ & \text { Cardiovascular Event Lowering } \\ \text { GLP-1 } & \text { Glucagon-like peptide-1 } \\ \text { GLP-1 RA } & \text { Glucagon-like peptide-1 receptor } \\ & \text { agonist } \\ \text { HF } & \text { Heart failure } \\ \text { LEADER } & \text { Liraglutide Effect and Action in } \\ & \text { Diabetes: Evaluation of of } \\ & \text { Cardiovascular Outcomes Results } \\ \text { MACE } & \text { Major adverse cardiac events } \\ \text { MI } & \text { Myocardial infarction } \\ \text { MNT } & \text { Medical nutrition therapy } \\ \text { RCT } & \text { Randomised clinical trial } \\ \text { SGLT2 } & \text { Sodium-glucose cotransporter-2 } \\ & \end{array}$




$\begin{array}{ll}\text { SGLT2i } & \begin{array}{l}\text { Sodium-glucose cotransporter-2 } \\ \text { inhibitor }\end{array} \\ \text { SMBG } & \begin{array}{l}\text { Self-monitoring of blood glucose } \\ \text { Sulfonylurea }\end{array} \\ \text { SU } & \begin{array}{l}\text { Trial to Evaluate Cardiovascular } \\ \text { and Other Long-term Outcomes } \\ \text { with Semaglutide in Subjects } \\ \text { with Type 2 Diabetes }\end{array} \\ & \text { Type 2 diabetes mellitus } \\ & \text { Thiazolidinedione } \\ \text { T2DM } & \text { UK Prospective Diabetes Study } \\ \text { TZD } & \end{array}$

\section{Introduction}

The goals of treatment for type 2 diabetes are to prevent or delay complications and maintain quality of life (Fig. 1). This requires control of glycaemia and cardiovascular risk factor management, regular follow-up and, importantly, a patientcentred approach to enhance patient engagement in self-care activities [1]. Careful consideration of patient factors and preferences must inform the process of individualising treatment goals and strategies [2, 3].

This consensus report addresses the approaches to management of glycaemia in adults with type 2 diabetes, with the goal of reducing complications and maintaining quality of life in the context of comprehensive cardiovascular risk management and patient-centred care. The principles of how this can be achieved are summarised in Fig. 1 and underpin the approach to management and care. These recommendations are not generally applicable to patients with monogenic diabetes, secondary diabetes or type 1 diabetes, or to children.

\section{Data sources, searches and study selection}

The writing group accepted the 2012 [4] and 2015 [5] editions of this position statement as a starting point. To identify newer evidence, a search was conducted on PubMed for randomised clinical trials (RCTs), systematic reviews and meta-analyses published in English between 1 January 2014 and 28 February 2018; eligible publications examined the effectiveness or safety of pharmacological or non-pharmacological interventions in adults with type 2 diabetes mellitus. Reference lists were scanned in eligible reports to identify additional articles relevant to the subject. Details on the keywords and the search strategy are available at https://doi.org/10.17632/ h5rcnxpk8w.1. Papers were grouped according to subject and the authors reviewed this new evidence to inform the consensus recommendations. The draft consensus recommendations were peer reviewed (see Acknowledgements), and suggestions incorporated as deemed appropriate by the authors. Nevertheless, though evidence based, the recommendations presented herein are the opinions of the authors.

\section{The rationale, importance and context of glucose-lowering treatment}

Lifestyle management, including medical nutrition therapy (MNT), physical activity, weight loss, counselling for smoking cessation, and psychological support, often delivered in the context of diabetes self-management education and support (DSMES), are fundamental aspects of diabetes care. The expanding number of glucose-lowering treatments - from behavioural interventions to medications and surgery-and growing information about their benefits and risks provides more options for people with diabetes and providers, but can complicate decision making. In this consensus statement, we attempt to provide an approach that summarises a large body of recent evidence for practitioners in the USA and Europe.

Marked hyperglycaemia is associated with symptoms including frequent urination, thirst, blurred vision, fatigue and recurring infections. Beyond alleviating symptoms, the aim of blood glucose lowering (hereafter, referred to as glycaemic management) is to reduce long-term complications of diabetes. Good glycaemic management yields substantial and enduring reductions in onset and progression of microvascular complications. This benefit has been demonstrated most clearly early in the natural history of the disease in studies using metformin, sulfonylureas and insulin but is supported by more recent studies with other medication classes. The greatest absolute risk reduction (ARR) comes from improving poor glycaemic control, and a more modest reduction results from near normalisation of glycaemia [6]. The impact of glucose control on macrovascular complications is less certain. Because the benefits of intensive glucose control emerge slowly, while the harms can be immediate, people with longer life expectancy have more to gain from intensive glucose control. A reasonable $\mathrm{HbA}_{1 \mathrm{c}}$ target for most non-pregnant adults with sufficient life expectancy to see microvascular benefits (generally $\sim 10$ years) is around $53 \mathrm{mmol} / \mathrm{mol}$ (7\%) or less [6]. Glycaemic treatment targets should be individualised based on patient preferences and goals, risk of adverse effects of therapy (e.g. hypoglycaemia and weight gain) and patient characteristics, including frailty and comorbid conditions [2].

Atherosclerotic cardiovascular disease (ASCVD) is the leading cause of death in people with type 2 diabetes [7]. Diabetes confers substantial independent ASCVD risk, and most people with type 2 diabetes have additional risk factors such as hypertension, dyslipidaemia, obesity, physical inactivity, chronic kidney disease (CKD) and smoking. Numerous studies have demonstrated the benefits of controlling modifiable ASCVD risk factors in people with diabetes. Substantial reductions in ASCVD events and death are seen when multiple ASCVD risk factors are addressed simultaneously, with long-standing benefits $[8,9]$. Comprehensive implementation of evidence-based interventions has likely contributed to the significant reductions in ASCVD events and mortality seen in 


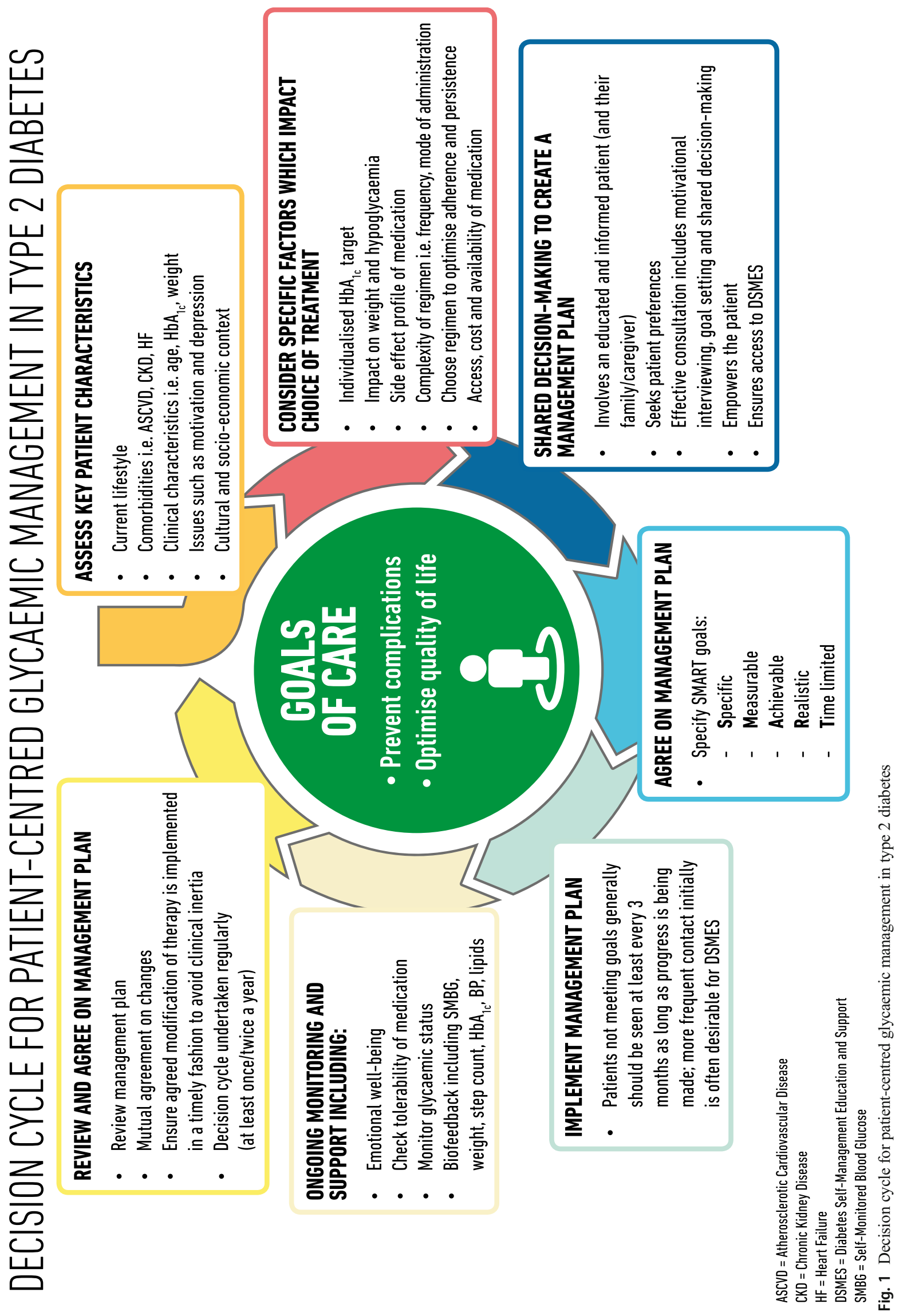


people with diabetes in recent decades [10]. ASCVD risk management in its many forms is an essential part of diabetes management that is beyond the scope of this statement, but physicians should be aware of the importance of multifactorial treatment in type 2 diabetes [7].

\section{Glucose management: monitoring}

Glycaemic management is primarily assessed with the $\mathrm{HbA}_{1 \mathrm{c}}$ test, which was the measure studied in trials demonstrating the benefits of glucose lowering [2]. The performance of the test is generally excellent for National Glycohemoglobin Standardization Program (NGSP)-certified assays and laboratories (www.ngsp.org) [11]. As with any laboratory test, $\mathrm{HbA}_{1 \mathrm{c}}$ has limitations [2]. Because there is variability in the measurement of $\mathrm{HbA}_{1 \mathrm{c}}$, clinicians should exercise judgement, particularly when the result is close to the threshold that might prompt a change in therapy. $\mathrm{HbA}_{1 \mathrm{c}}$ results may be discrepant from the patient's true mean glycaemia in certain racial and ethnic groups, and in conditions that alter red blood cell turnover, such as anaemia, end-stage renal disease (ESRD; especially with erythropoietin therapy), and pregnancy, or if an $\mathrm{HbA}_{1 \mathrm{c}}$ assay sensitive to haemoglobin variants is used in someone with sickle cell trait or other haemoglobinopathy. Discrepancies between measured $\mathrm{HbA}_{1 \mathrm{c}}$ and measured or reported glucose levels should prompt consideration that one of these may not be reliable [12].

Regular self-monitoring of blood glucose (SMBG) may help with self-management and medication adjustment, particularly in individuals taking insulin. SMBG plans should be individualised. People with diabetes and the healthcare team should use the data in an effective and timely manner. In people with type 2 diabetes not using insulin, routine glucose monitoring is of limited additional clinical benefit while adding burden and cost [13, 14]. However, for some individuals, glucose monitoring can provide insight into the impact of lifestyle and medication management on blood glucose and symptoms, particularly when combined with education and support. Novel technologies, such as continuous or flash glucose monitoring, provide more information. However, in type 2 diabetes, they have been associated with only modest benefits [15].

\section{Principles of care}

\section{Consensus recommendation}

Providers and healthcare systems should prioritise the delivery of patient-centred care.

Providing patient-centred care that acknowledges multi-morbidity, and is respectful of and responsive to individual patient preferences and barriers, including the differential costs of therapies, is essential to effective diabetes management [16].
Shared decision making, facilitated by decision aids that show the absolute benefit and risk of alternative treatment options, is a useful strategy to arrive at the best treatment course for an individual [17-20]. Providers should evaluate the impact of any suggested intervention, including self-care regimens, in the context of cognitive impairment, limited literacy, distinct cultural beliefs and individual fears or health concerns given their impact on treatment efficacy.

\section{DSMES}

\section{Consensus recommendation}

All people with type 2 diabetes should be offered access to ongoing DSMES programmes.

DSMES is a key intervention to enable people with diabetes to make informed decisions and to assume responsibility for dayto-day diabetes management. DSMES is central to establishing and implementing the principles of care (Fig. 1). DSMES programmes usually involve face-to-face contact in group or individual sessions with trained educators, and key components are shown in the Table 1 [21-25]. While DSMES should be available on an ongoing basis, critical junctures when DSMES should occur include at diagnosis, annually, when complications arise and during transitions in life and care [22].

DSMES programmes delivered from diagnosis can promote medication adherence, healthy eating and physical activity, and increase self-efficacy. In type 2 diabetes, high-quality evidence has consistently shown that DSMES is a costeffective intervention in the healthcare systems studied. DSMES significantly improves clinical and psychological outcomes, improves glycaemic control, reduces hospital admissions, improves patient knowledge, and reduces the risk of all-cause mortality [22, 26-31]. The best outcomes are achieved in those programmes with a theory-based and structured curriculum, and with contact time of over $10 \mathrm{~h}$. While online programmes may reinforce learning, there is little evidence they are effective when used alone [27].

\section{Consensus recommendation}

Facilitating medication adherence should be specifically considered when selecting glucose-lowering medications.

Suboptimal adherence, including poor persistence, to therapy affects almost half of people with diabetes, leading to suboptimal glycaemic and cardiovascular disease (CVD) risk factor control as well as increased risk of diabetes complications, mortality, hospital admissions and healthcare costs [32-36]. Though this consensus recommendation focuses on medication adherence (including persistence), the principles 
Table 1 Key components of DSMES [21, 23-25]

Table 1. Key components of DSMES [21, 23-25]

- Evidence-based

- Individualised to the needs of the person, including language and culture

- Has a structured theory-driven written curriculum with supporting materials

- Delivered by trained and competent individuals (educators) who are quality assured

- Delivered in group or individual settings

- Aligns with the local population needs

- Supports the person and their family in developing attitudes, beliefs, knowledge and skills to self-manage diabetes

- Includes core content, i.e. diabetes pathophysiology and treatment options; medication usage; monitoring, preventing, detecting and treating acute and chronic complications; healthy coping with psychological issues and concerns; problem solving and dealing with special situations (i.e. travel, fasting)

- Available to patients at critical times (i.e. at diagnosis, annually, when complications arise and when transitions in care occur)

- Includes monitoring of patient progress, including health status, quality of life

- Quality audited regularly

DSMES is a critical element of care for all people with diabetes and is the ongoing process of facilitating the knowledge, skills and ability necessary for diabetes self-care as well as activities that assist a person implementing and sustaining behaviours needed to manage their diabetes on an ongoing basis

National organisations in the USA and Europe have published standards to underpin DSMES. In the USA these are defined as DSMES 'Services' whereas in Europe they are often referred to as 'programmes'. Nevertheless, the broad components are similar

are pertinent to all aspects of diabetes care. Multiple factors contribute to inconsistent medication use and treatment discontinuation, including patient-perceived lack of medication efficacy, fear of hypoglycaemia, lack of access to medication and adverse effects of medication [37]. Medication adherence (including persistence) varies across medication classes and careful consideration of these differences may help improve outcomes [38]. Ultimately, patient preference is a major factor driving the choice of medication. Even in cases where clinical characteristics suggest the use of a particular medication based on the available evidence from clinical trials, patient preferences regarding route of administration, injection devices, side effects or cost may prevent their use by some individuals [39].

Therapeutic inertia, sometimes referred to as clinical inertia, refers to failure to intensify therapy when treatment targets are not met. The causes of therapeutic inertia are multifactorial, occurring at the level of the practitioner, patient and/or healthcare system [40]. Interventions targeting therapeutic inertia have facilitated improved glycaemic control and timely insulin intensification $[41,42]$. For example, multidisciplinary teams that include nurse practitioners or pharmacists may help reduce therapeutic inertia [43, 44]. A fragmented healthcare system may contribute to therapeutic inertia and impair delivery of patient-centred care. A coordinated chronic care model, including self-management support, decision support, delivery system design, clinical information systems, and community resources and policies, promotes interaction between more empowered patients and better prepared and proactive healthcare teams [45].

\section{Recommended process for glucose-lowering medication selection: where does new evidence from cardiovascular outcomes trials fit in?}

In prior consensus statements, efficacy in reducing hyperglycaemia, along with tolerability and safety were primary factors in glucose-lowering medication selection. Patient preferences, glycaemic targets, comorbidities, polypharmacy, side effects and cost were additional important considerations. For every individual, the choice of glucose-lowering medication should be underpinned by lifestyle management, DSMES and the patient-centred care principles outlined in Fig. 1.

Figure 2 describes our new consensus approach to glucose lowering with medications in type 2 diabetes. Because of the new evidence for the benefit of specific medications to reduce mortality, heart failure (HF) and progression of renal disease in the setting of established CVD, their use was considered 


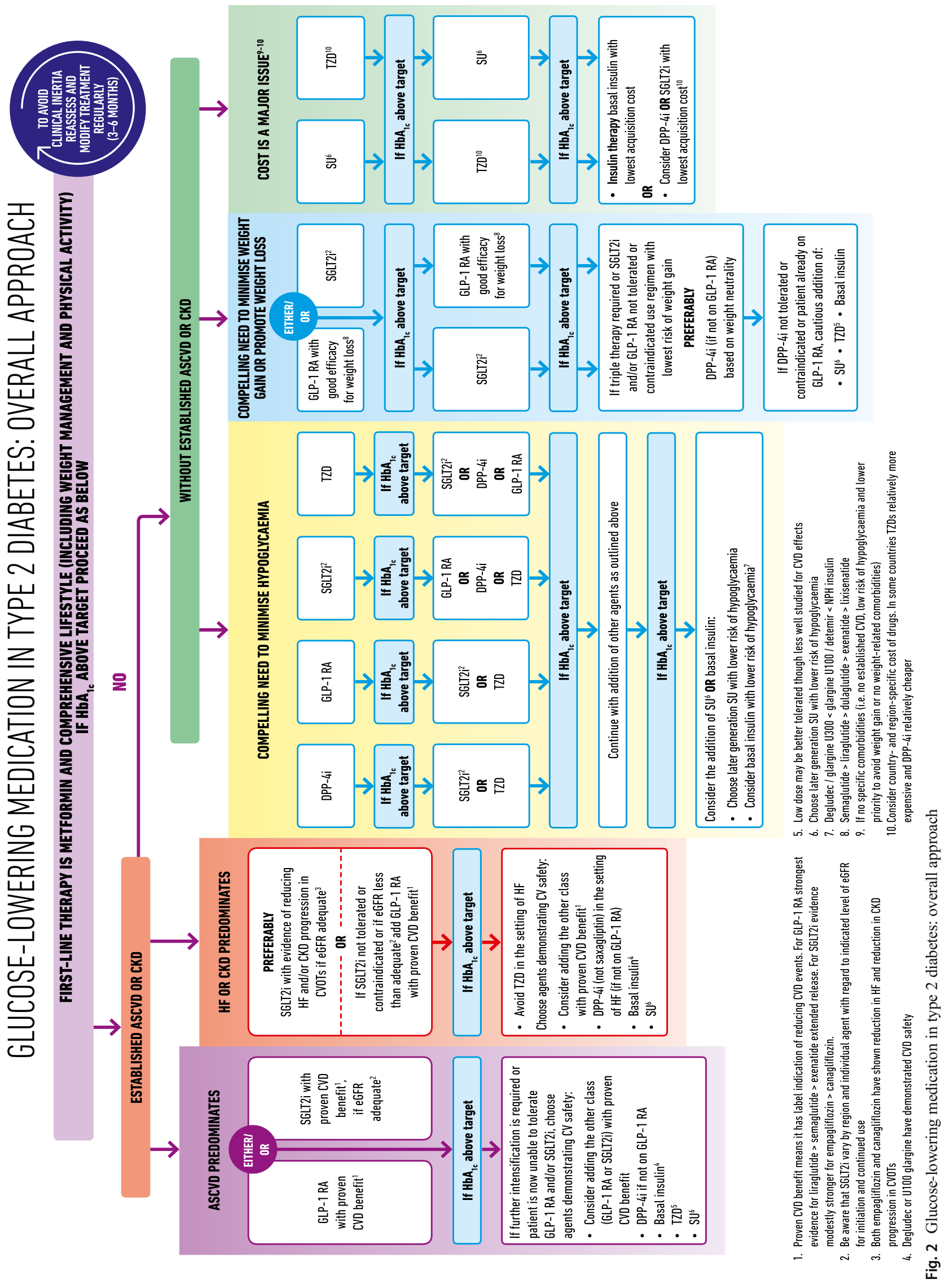


compelling in this patient group. Thus, we recommend that providers consider a history of CVD very early in the process of treatment selection. Other factors affect the choice of glucose-lowering medications, particularly in the setting of patient-centred care. In addition to CVD, we recommend early consideration of weight, hypoglycaemic risk, treatment cost and other patient-related factors that may influence treatment selection (Figs 2, 3, 4, 5, 6).

\section{Implications of new evidence from cardiovascular outcomes trials}

The major change from prior consensus reports is based on new evidence that specific sodium-glucose cotransporter-2 (SGLT2) inhibitors or glucagon-like peptide-1 (GLP-1) receptor agonists improve cardiovascular outcomes, as well as secondary outcomes such as HF and progression of renal disease, in patients with established CVD or CKD. Therefore, an important early step in this new approach (Fig. 3) is to consider the presence or absence of ASCVD, HF and CKD, conditions in aggregate affecting $15-25 \%$ of the population with type 2 diabetes. While the new evidence supporting the use of particular medications in patients who also have established CVD or are at high risk of CVD is derived from large cardiovascular outcomes trials (CVOTs) demonstrating substantial benefits over 2-5 years, it is important to remember that each trial constitutes a single experiment. Within each drug class, results have been heterogeneous. It is not clear whether there are true drug class effects with different findings for individual medications due to differences in trial design and conduct, or whether there are real differences between medications within a drug class due to properties of the individual compounds. Where the current evidence is strongest for a specific medication within a class, it is noted. The ADA's 'Standards of medical care in diabetes' will align with this document and will be updated to reflect new evidence as it emerges from ongoing clinical trials.

\section{Consensus recommendation}

Among patients with type 2 diabetes who have established ASCVD, SGLT2 inhibitors or GLP-1 receptor agonists with proven cardiovascular benefit are recommended as part of glycaemic management (Figs 2 and 3).

ASCVD is defined somewhat differently across trials, but all trials enrolled individuals with established CVD (e.g. myocardial infarction $[\mathrm{MI}]$, stroke, any revascularisation procedure) while variably including related conditions compatible with clinically significant atherosclerosis (e.g. transient ischaemic attack, hospitalised unstable angina, amputation, congestive heart failure New York Heart Association [NYHA] class IIIII, $>50 \%$ stenosis of any artery, symptomatic or asymptomatic coronary artery disease documented by imaging, CKD with estimated GFR [eGFR] $<60 \mathrm{ml} \mathrm{min}^{-1}[1.73 \mathrm{~m}]^{-2}$ ). Most trials also included a 'risk factor only' group with entry criteria based on age and usually the presence of two or more cardiac risk factors [46]. Trials were designed to evaluate cardiovascular safety (i.e. statistical non-inferiority compared with placebo), but several showed ASCVD outcome benefit (i.e. statistical superiority compared with placebo), including, in some cases, mortality.

Among GLP-1 receptor agonists, liraglutide, studied in the Liraglutide Effect and Action in Diabetes: Evaluation of Cardiovascular Outcomes Results (LEADER) trial $(n=9340)$ demonstrated an ARR of $1.9 \%$ with an HR of 0.87 (95\% CI $0.78,0.97 ; p=0.01$ for superiority) for the primary composite outcome of cardiovascular death, non-fatal MI and non-fatal stroke (major adverse cardiac events [MACE]) compared with placebo over 3.8 years. Each component of the composite contributed to the benefit, and the HR for cardiovascular death was 0.78 (95\% CI 0.66, 0.93; $p=0.007$; ARR 1.7\%). The LEADER trial also demonstrated an HR of 0.85 (95\% CI, 0.74 to 0.97 ; $p=0.02$; ARR $1.4 \%$ ) for all-cause mortality [47]. In the Trial to Evaluate Cardiovascular and Other Long-term Outcomes with Semaglutide in Subjects with Type 2 Diabetes (SUSTAIN 6) $(n=3297)$, semaglutide compared with placebo demonstrated an ARR of $2.3 \%$ with HR 0.74 for MACE $(95 \%$ CI 0.58, 0.95; $p=0.02$ for superiority) over 2.1 years, but the reduction in events appeared to be driven by the rate of stroke, rather than CVD death [48]. The Exenatide Study of Cardiovascular Event Lowering (EXSCEL) compared exenatide extended-release with placebo over 3.2 years in 14,752 participants with type 2 diabetes. While the medication was safe (non-inferior), the HR for MACE in the entire trial was 0.91 (95\% CI $0.83,1.0 ; p=$ 0.06 ) not reaching the threshold for demonstrated superiority vs placebo; ARR was 0.8\% [49]. All-cause death was lower in the exenatide arm (ARR 1\%, HR 0.86 [95\% CI 0.77, 0.97]), but it was not considered to be statistically significant in the hierarchical testing procedure applied. Lixisenatide, a short-acting GLP-1 receptor agonist, did not demonstrate CVD benefit or harm in a trial of patients recruited within 180 days of an acute coronary syndrome admission [50]. Taken together, it appears that among patients with established CVD, some GLP-1 receptor agonists may provide cardiovascular benefit, with the evidence of benefit strongest for liraglutide, favourable for semaglutide, and less certain for exenatide. There is no evidence of cardiovascular benefit with lixisenatide. Adverse effects for the class are discussed in the section 'The full range of therapeutic options: lifestyle management, medication and obesity management'.

Among the SGLT2 inhibitors, empagliflozin compared with placebo was studied in the Empagliflozin, Cardiovascular Outcome Event Trial in Type 2 Diabetes Mellitus Patients 


\section{CHOOSING GLUCOSE-LOWERING MEDICATION IN THOSE WITH ESTABLISHED ATHEROSCLEROTIC CARDIOVASCULAR DISEASE (ASCVD) OR CHRONIC KIDNEY DISEASE (CKD)}

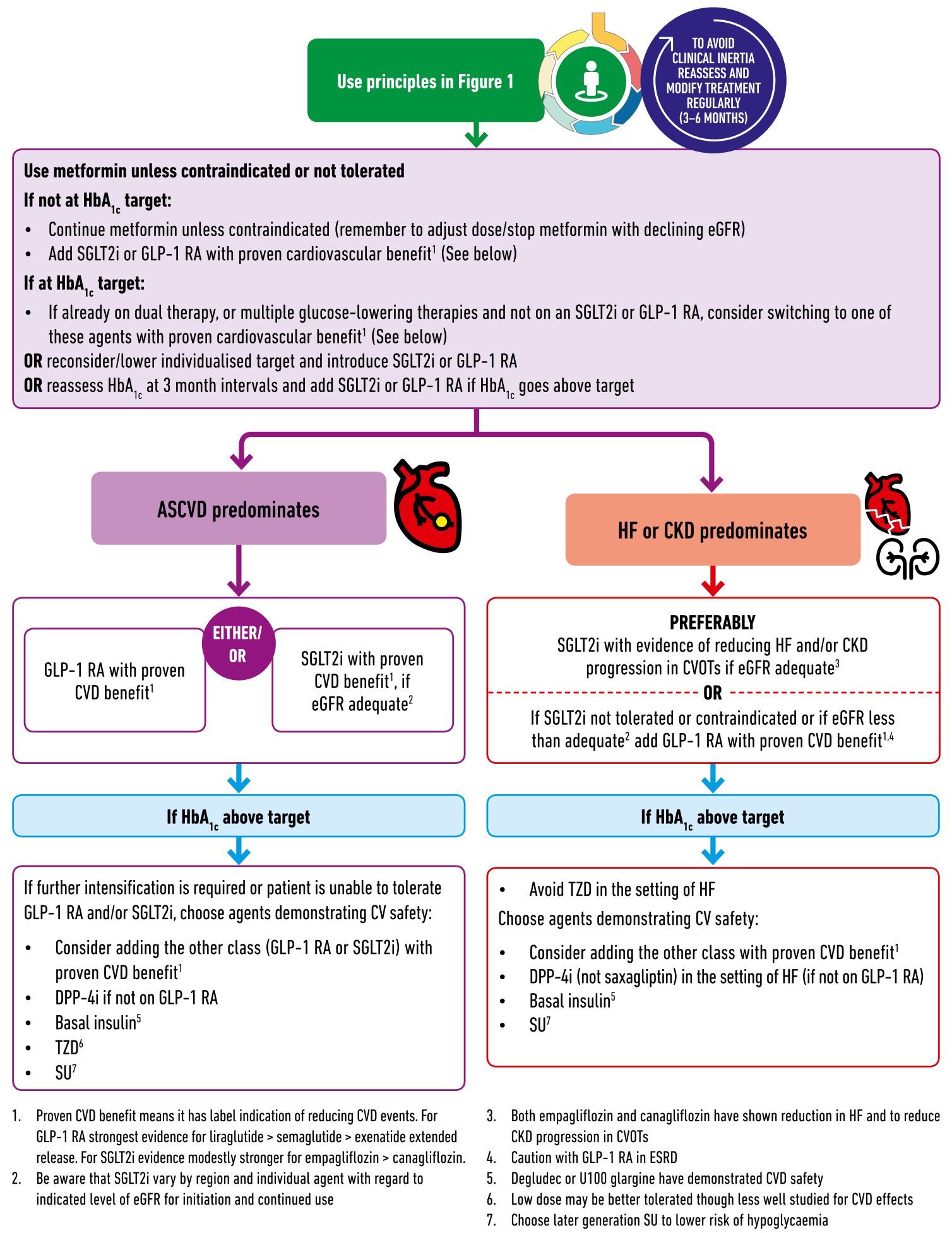

Fig. 3 Choosing glucose-lowering medication in those with established atherosclerotic cardiovascular disease (ASCVD) or chronic kidney disease (CKD) 


\section{CHOOSING GLUCOSE-LOWERING MEDICATION IF COMPELLING NEED TO MINIMISE WEIGHT $\downarrow$ :::: GAIN OR PROMOTE WEIGHT LOSS}

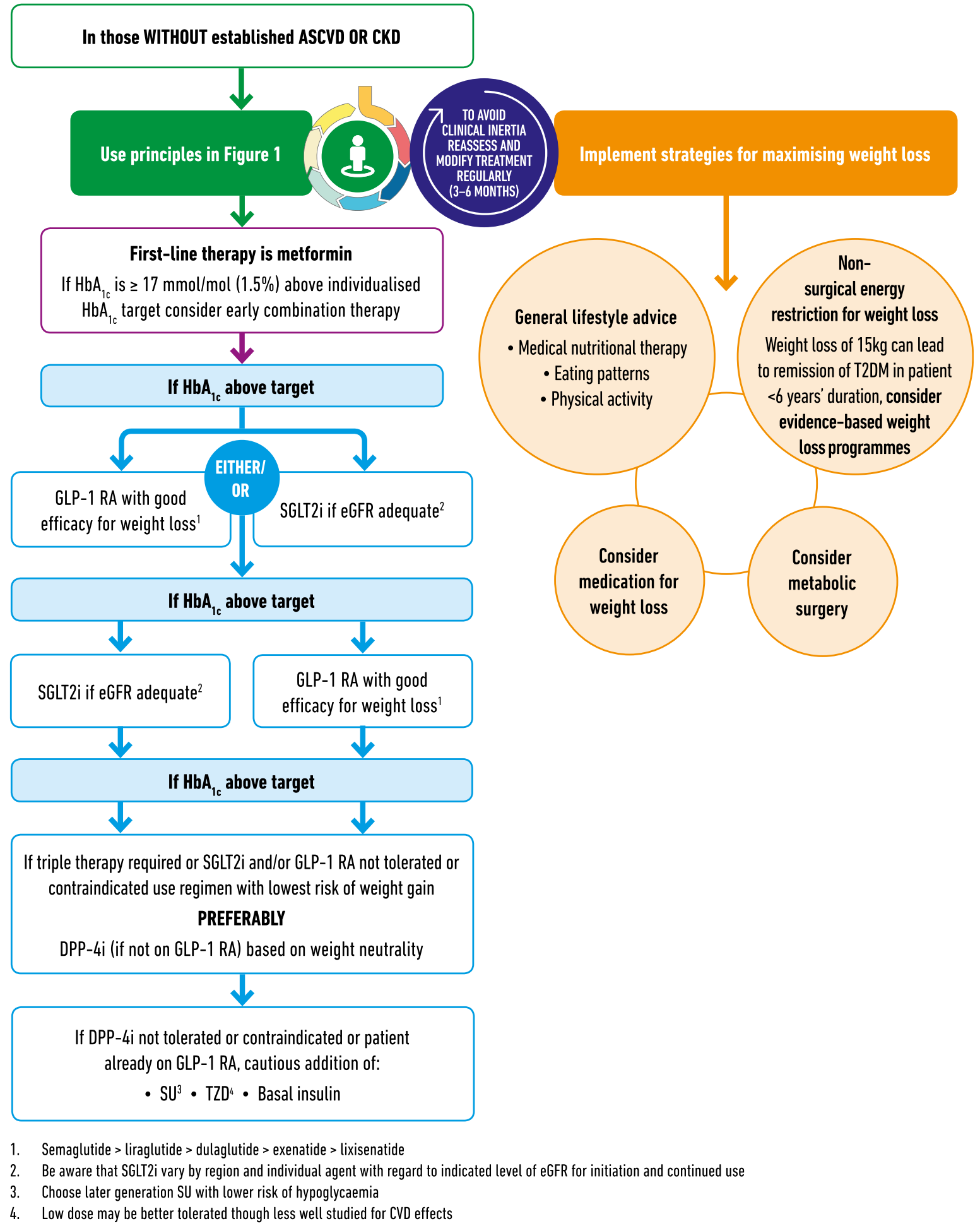

Fig. 4 Choosing glucose-lowering medication if compelling need to minimise weight gain or promote weight loss 


\section{CHOOSING GLUCOSE-LOWERING MEDICATION IF COMPELLING NEED TO MINIMISE HYPOGLYCAEMIA}

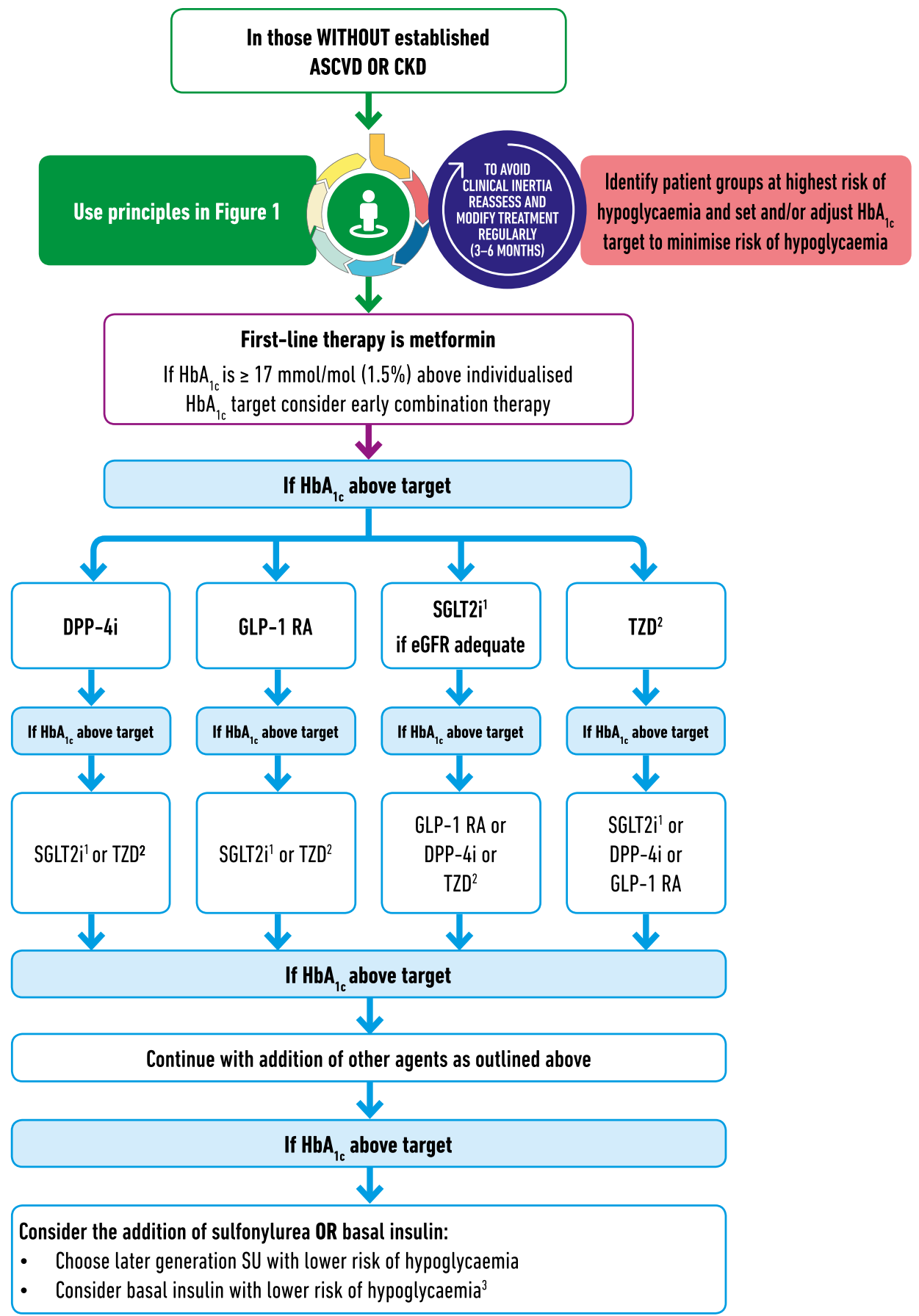

1. Be aware that SGLT2i vary by region and individual agent with regard to indicated level of eGFR for initiation and continued use

2. Low dose TZDs are better tolerated

3. Degludec / glargine U300 < glargine U100 / detemir < NPH insulin

Fig. 5 Choosing glucose-lowering medication if compelling need to minimise hypoglycaemia 


\section{CHOOSING GLUCOSE-LOWERING MEDICATION IF COST IS A MAJOR ISSUE

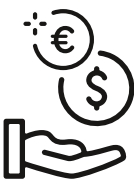

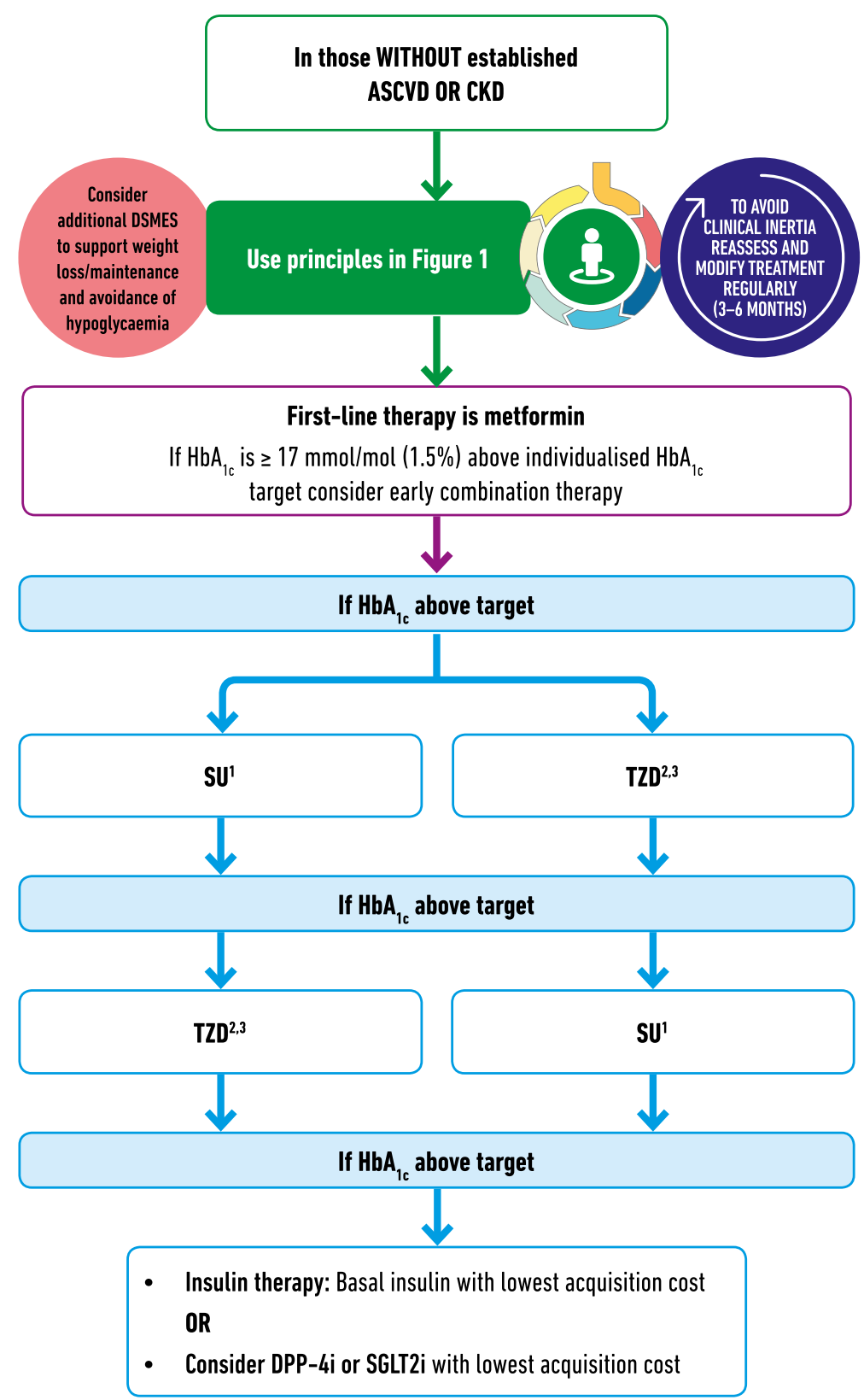

1. Choose later generation SU to minimise risk of hypoglycaemia

2. Consider country- and region-specific cost of drugs. In some countries, TZD relatively more expensive and DPP-4i relatively cheaper

3. Low-dose TZDs are better tolerated

Fig. 6 Choosing glucose-lowering medication if cost is a major issue

(EMPA-REG OUTCOME) in 7020 participants with type 2 diabetes and CVD. With a median follow-up of 3.1 years, the
ARR was $1.6 \%$ and the HR was 0.86 (95\% CI 0.74, 0.99; $p=$ 0.04 for superiority) for the primary composite endpoint of non- 
fatal MI, non-fatal stroke and cardiovascular death. The ARR was $2.2 \%$ and the HR was 0.62 (95\% CI $0.49,0.77 ; p<0.001)$ for cardiovascular death [51]. The ARR was $2.6 \%$ and the HR was $0.68(95 \% \mathrm{CI}, 0.57,0.82 ; p<0.001)$ for death from any cause. Canagliflozin compared with placebo was studied in the Canagliflozin Cardiovascular Assessment Study (CANVAS) Program (comprised of two similar trials, CANVAS and CANVAS-Renal; $n=10,142$ ) in participants with type 2 diabetes, $66 \%$ of whom had a history of CVD. Participants were followed for a median of 3.6 years. In the combined analysis of the two trials, the primary composite endpoint of MI, stroke or cardiovascular death was reduced with canagliflozin (26.9 vs 31.5 participants per patient-year with placebo; HR $0.86,95 \%$ CI $0.75,0.97 ; p=0.02$ ) for superiority in the pooled analysis, with consistent findings in the component studies. Though there was a trend towards benefit for cardiovascular death, the difference from placebo was not statistically significant in the CANVAS Program [52]. For the SGLT2 inhibitors studied to date, it appears that among patients with established CVD, there is likely cardiovascular benefit, with the evidence of benefit modestly stronger for empagliflozin than canagliflozin. Adverse effects for the class are discussed in the section 'The full range of therapeutic options: lifestyle management, medication and obesity management'.

While the evidence of an ASCVD outcomes benefit for GLP-1 receptor agonists and SGLT2 inhibitors has been demonstrated for people with established ASCVD, the evidence of benefit beyond glucose lowering has not been demonstrated in those without ASCVD. Indeed, in subgroup analyses of these trials, lower risk individuals have not been observed to have an ASCVD benefit. While this may be due to the short time frame of the studies and the low event rate in those without ASCVD, the finding is consistent across the reported trials. Overall, CVOTs of dipeptidyl peptidase-4 (DPP-4) inhibitors have demonstrated safety, i.e. non-inferiority relative to placebo, for the primary MACE endpoint, but not cardiovascular benefit.

The available evidence for cardiovascular event reduction in patients with type 2 diabetes and clinical CVD is derived from trials in which the participants were not meeting glycaemic targets $\left(\mathrm{HbA}_{1 \mathrm{c}} \geq 53 \mathrm{mmol} / \mathrm{mol}[\geq 7 \%]\right.$ at baseline). Furthermore, most ( $\sim 70 \%$ across trials) participants were treated with metformin at baseline. Thus, we recommend that patients with clinical CVD not meeting individualised glycaemic targets while treated with metformin (or in whom metformin is contraindicated or not tolerated) should have an SGLT2 inhibitor or GLP-1 receptor agonist with proven benefit for cardiovascular risk reduction added to their treatment programme. There are no clinical trial data that support prescribing an SGLT2 inhibitor or GLP-1 receptor agonist with the intent of reducing cardiovascular risk in patients with an $\mathrm{HbA}_{1 \mathrm{c}}<53 \mathrm{mmol} / \mathrm{mol}(<7 \%)$. Limited data suggest that there is no heterogeneity in the cardiovascular benefits of SGLT2 inhibitors or GLP-1 receptor agonists as a function of background glucose-lowering therapy. Thus, background glucose-lowering therapy in patients with clinical CVD arguably is not pertinent in clinical decision making. However, dose adjustment or discontinuation of background medications may be required to avoid hypoglycaemia when adding a new agent to a regimen containing insulin, sulfonylurea or glinide therapy, particularly in patients at or near glycaemic goals. Full efforts to achieve glycaemic and blood pressure targets and to adhere to lipid, antiplatelet, antithrombotic and tobacco cessation guidelines [7] should continue after an SGLT2 inhibitor or GLP-1 receptor agonist is added, as such efforts were integral to all studies that have demonstrated cardiovascular benefit of these agents.

\section{Consensus recommendation}

Among patients with ASCVD in whom HF coexists or is of special concern, SGLT2 inhibitors are recommended (Figs 2 and 3 ).

Patients with type 2 diabetes are at increased risk of $\mathrm{HF}$ [53]. In the EMPA-REG OUTCOME and CANVAS CVOT studies testing SGLT2 inhibitors, which enrolled participants with ASCVD, $>85 \%$ of participants did not have symptomatic $\mathrm{HF}$ at baseline. Yet, in both trials there was a clinically and statistically significant reduction in hospitalisation for HF for the SGLT2 inhibitor as compared with placebo. In the EMPAREG OUTCOME study with empagliflozin [54], the ARR was $1.4 \%$, and the HR $0.65(95 \%$ CI $0.50,0.85)$ and in the CANVAS Program with canagliflozin the HR was 0.67 (95\% CI $0.52,0.87$ ), with a rate of hospitalised HF of 5.5 vs 8.7 events per 1000 patient-years [55]. Because HF was neither well characterised at baseline nor as carefully adjudicated as it would have been in a trial specifically designed to evaluate $\mathrm{HF}$ outcomes, and because HF was a secondary endpoint in the trials, further ongoing studies are required to conclusively address the issue. That said, the significant reduction in hospitalisation for HF demonstrated in the two study populations and the consistency across two independent trial programmes suggest to us that treatment with SGLT2 inhibitors in the setting of clinical HF may provide substantial benefit and should be specifically considered in people with type 2 diabetes and ASCVD and HF.

In the GLP-1 receptor agonist studies LEADER, SUSTAIN 6 and EXSCEL, there was no significant effect on hospitalization for HF with HR 0.86 (95\% CI 0.71, 1.06), $1.11(95 \%$ CI $0.77,1.61)$ and 0.94 (95\% CI 0.78, 1.13), respectively [47-49]. Two short-term studies of liraglutide in patients with reduced ejection fraction suggested a lack of benefit in this setting $[56,57]$.

Among the recent cardiovascular safety outcomes trials testing DPP-4 inhibitors, the Saxagliptin Assessment of Vascular Outcomes Recorded in Patients with Diabetes 
Mellitus - Thrombolysis in Myocardial Infarction 53 (SAVOR-TIMI 53) study evaluating saxagliptin demonstrated a significant increased risk of $\mathrm{HF}$, with $3.5 \%$ risk of hospitalisation for HF vs $2.8 \%$ for placebo (HR 1.27; $95 \%$ CI $1.07,1.51 ; p=0.007$ ) [58]. In the subsequent Examination of Cardiovascular Outcomes with Alogliptin versus Standard of Care (EXAMINE) study of alogliptin there was no statistically significant difference in HF hospitalisation (3.9\% vs $3.3 \%$ with placebo) [59], and in the Trial Evaluating Cardiovascular Outcomes with Sitagliptin (TECOS), the rate of hospitalisation for HF was $3.1 \%$ in both sitagliptin- and placebotreated patients [60].

\section{Consensus recommendation}

For patients with type 2 diabetes and CKD, with or without CVD, consider the use of an SGLT2 inhibitor shown to reduce CKD progression or, if contraindicated or not preferred, a GLP-1 receptor agonist shown to reduce CKD progression (Figs 2 and 3 ).

Patients with type 2 diabetes and kidney disease are at an increased risk for cardiovascular events. A substantial number of participants with an eGFR of $30-60 \mathrm{ml} \mathrm{min}^{-1}[1.73 \mathrm{~m}]^{-2}$ were included in EMPA-REG OUTCOME, CANVAS, LEADER and SUSTAIN 6. An important finding in the studies was reduction of the primary ASCVD outcome even among participants with stage 3 CKD (eGFR $30-60 \mathrm{ml} \mathrm{min}{ }^{-1}[1.73 \mathrm{~m}]^{-2}$ ). For SGLT2 inhibitors, this contrasts with the glucose-lowering effect, which diminishes with declining eGFR.

In addition to the primary cardiovascular endpoints, most of the SGLT2 inhibitor and GLP-1 receptor agonist CVOTs reported benefit in renal endpoints, albeit as secondary outcomes. The renal outcome benefit has been most pronounced and consistent for SGLT2 inhibitors. EMPA-REG OUTCOME (empagliflozin) demonstrated an ARR 6.1\%, HR of $0.61(95 \%$ CI $0.53,0.70)$ for the composite outcome of new or worsening nephropathy (progression to urine albumin/creatinine ratio $>33.9 \mathrm{mg} / \mathrm{mmol}(>300 \mathrm{mg} / \mathrm{g}$ ), doubling of serum creatinine and ESRD, or death by ESRD). The most prevalent outcome component was the development of sustained albuminuria, but the other components were each significantly reduced relative to placebo [61]. CANVAS (canagliflozin) reported an HR of 1.7 (95\% CI 1.51, 1.91) for regression of albuminuria and a $40 \%$ reduction in risk in the composite outcome of eGFR, ESRD or renal death $(5.5 \mathrm{vs}$ 9.0 participants per 1000 patient-years; HR 0.60 ; 95\% CI $0.47,0.77$ ) [52]. Additional trials with primary renal endpoints are ongoing in high-risk renal populations. The Canagliflozin and Renal Endpoints in Diabetes with Established Nephropathy Clinical Evaluation (CREDENCE) trial examining canagliflozin in CKD with proteinuria has been stopped at a planned interim analysis for achieving the primary efficacy endpoint [62].
In LEADER and SUSTAIN 6, the GLP-1 receptor agonist liraglutide was associated with an ARR of $1.5 \%$ and an HR of 0.78 (95\% CI $0.67,0.92)$ for new or worsening nephropathy [63], and semaglutide demonstrated an ARR of $2.3 \%$ and an HR of 0.64 (95\% CI $0.46,0.88)$ for new or worsening nephropathy [48]. Progression of albuminuria was the most prevalent component of the composite renal endpoint, whereas the other components (doubling of serum creatinine, ESRD or renal death) did not contribute substantially to the benefit. In the DPP-4 inhibitor CVOTs, the DPP-4 inhibitors have been shown to be safe from a renal perspective, with modest reduction in albuminuria [64].

\section{The full range of therapeutic options: lifestyle management, medication and obesity management}

This section summarises the lifestyle, medication and obesity management therapies that lower glucose or improve other outcomes in patients with type 2 diabetes. A more comprehensive discussion of these issues is available elsewhere [3, 21, 65]. For more details on weight loss medications and metabolic surgery, see the section 'Obesity management beyond lifestyle intervention'. Basic information about specific options in each category of therapy is summarised in Table 2.

Lifestyle interventions, including MNT and physical activity, are effective and safe for improving glucose control in type 2 diabetes. For these reasons, they are recommended as firstline therapies from the time of diagnosis and as co-therapy for patients who also require glucose-lowering medications or metabolic surgery. Lifestyle management should be part of the ongoing discussion with individuals with type 2 diabetes at each visit.

\section{Lifestyle management}

\section{Consensus recommendation}

An individualised programme of MNT should be offered to all patients.

\section{Medical nutrition therapy}

MNT comprises education and support to help patients adopt healthy eating patterns. The goal of MNT is to manage blood glucose and cardiovascular risk factors to reduce risk for diabetes-related complications while preserving the pleasure of eating [21]. Two basic dimensions of MNT include dietary quality and energy restriction. Strategies directed at each dimension can improve glycaemic control. 


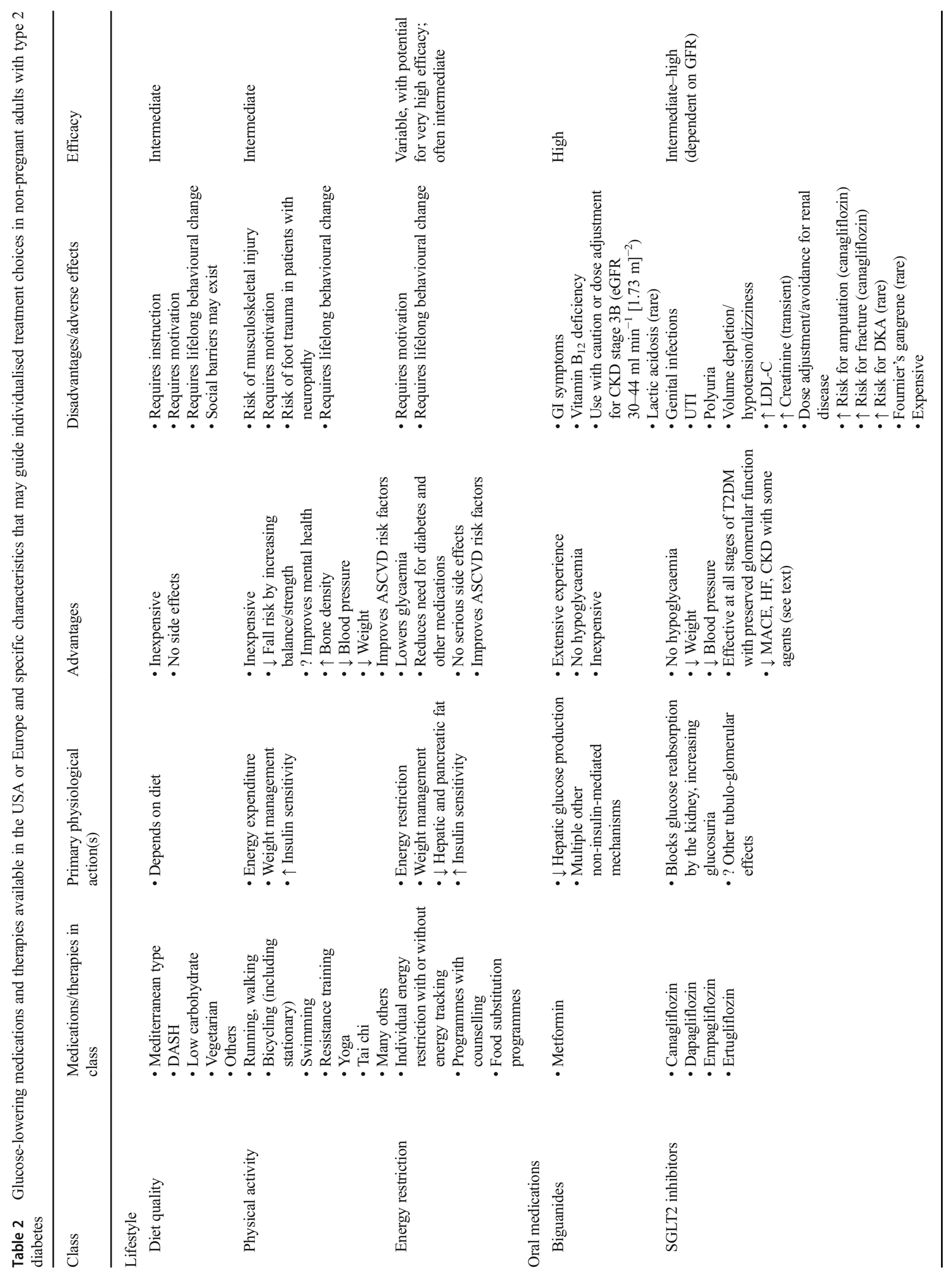




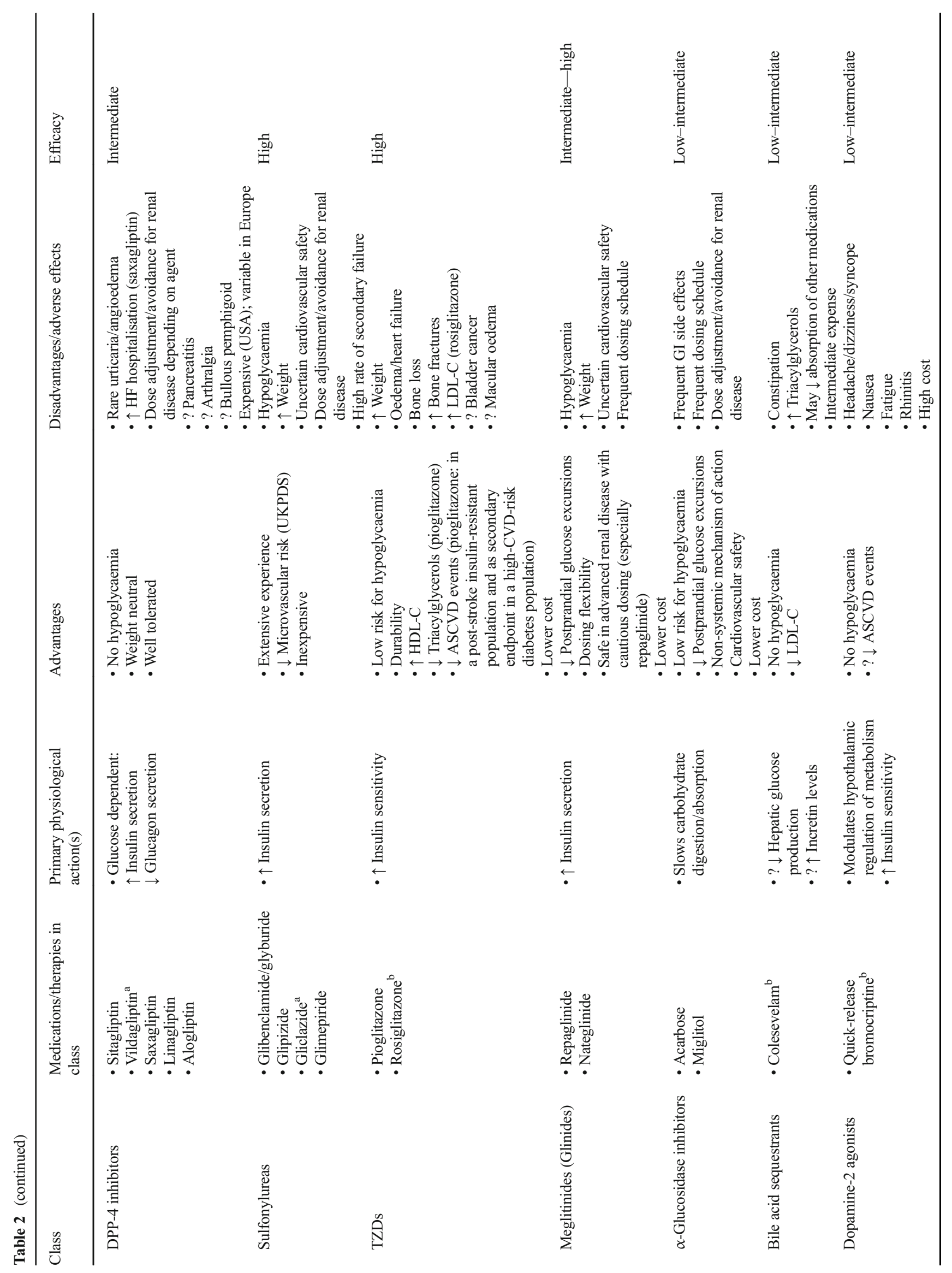




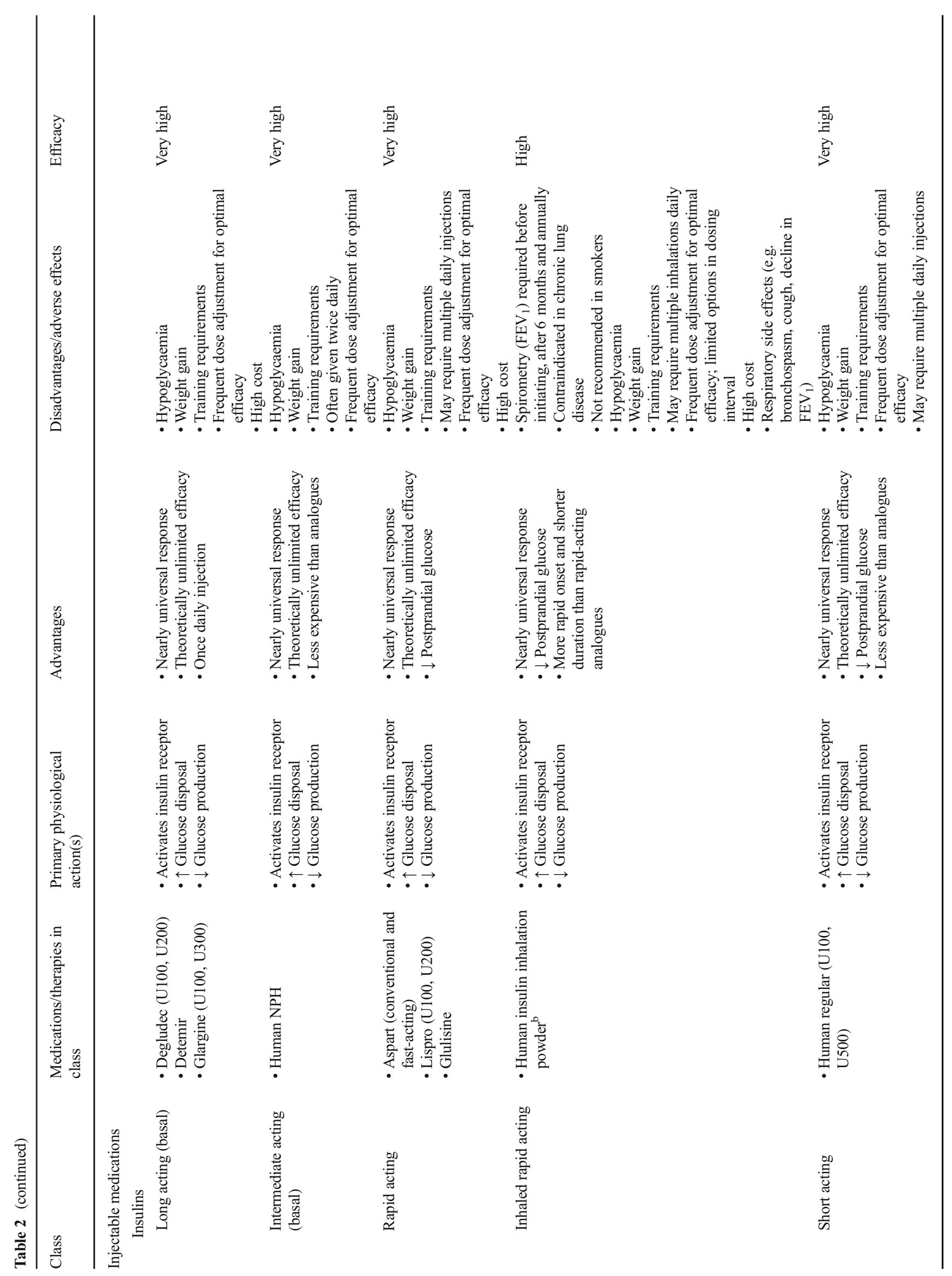




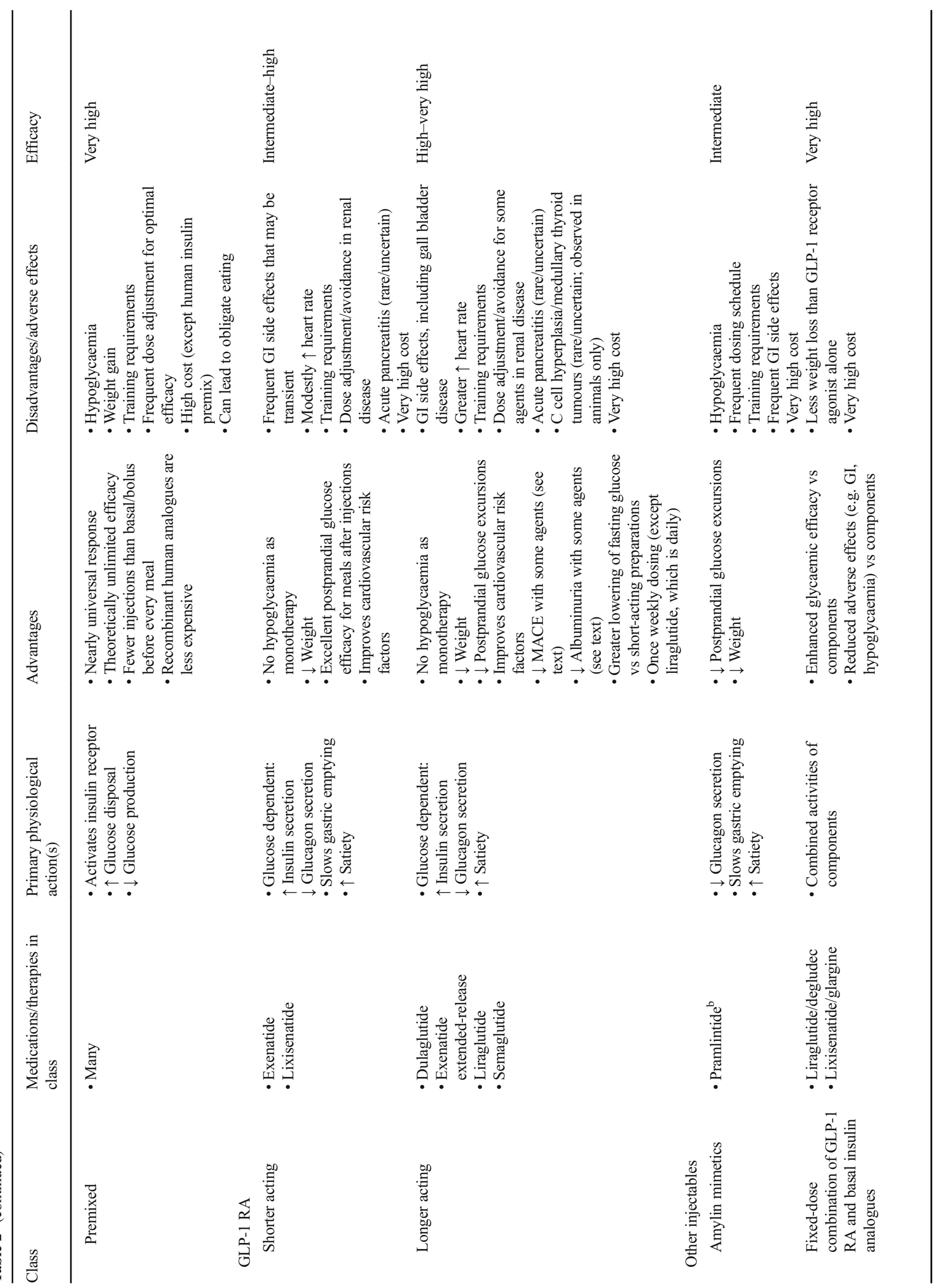




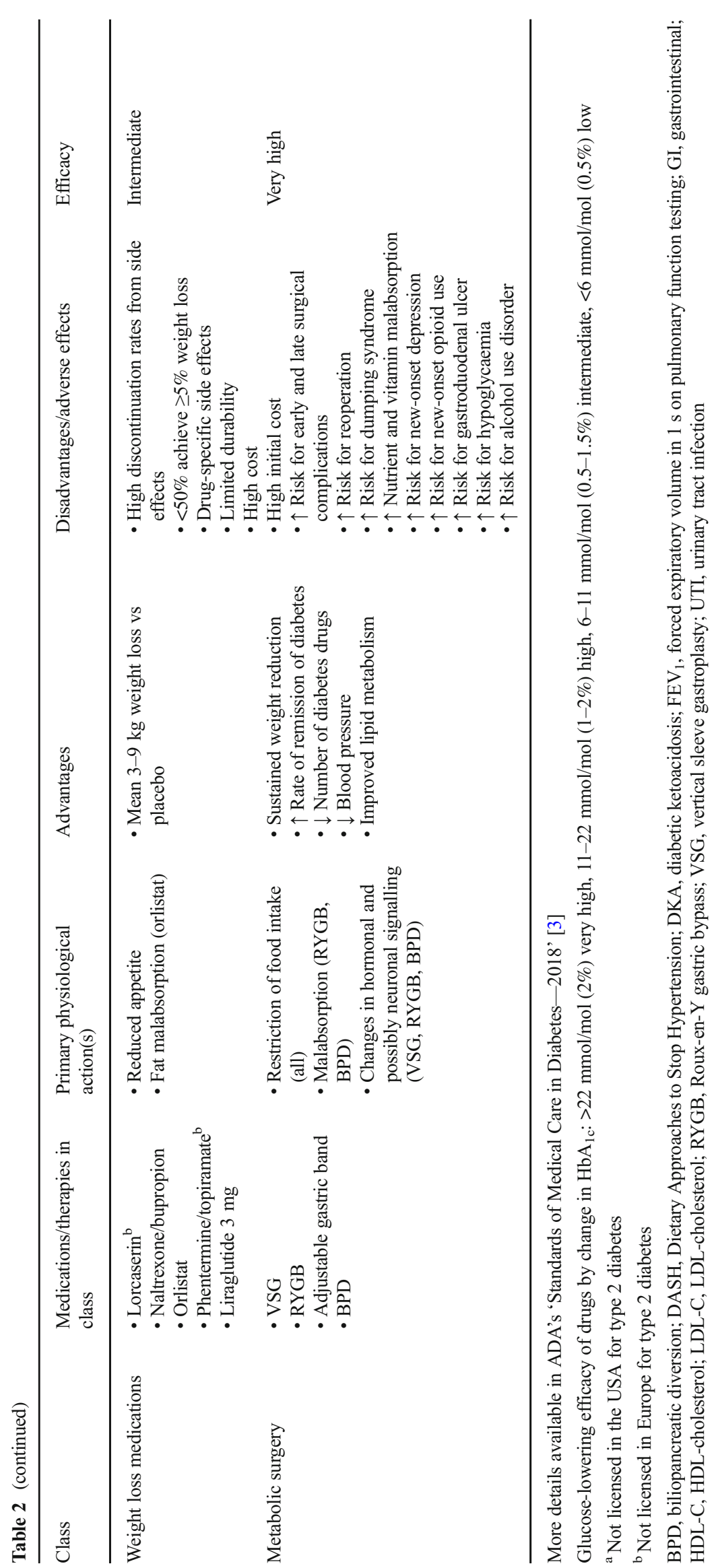


Dietary quality and eating patterns There is no single ratio of carbohydrate, proteins and fat intake that is optimal for every person with type 2 diabetes. Instead, there are many good options and professional guidelines usually recommend individually selected eating patterns that emphasise foods of demonstrated health benefit, that minimise foods of demonstrated harm and that accommodate patient preference and metabolic needs, with the goal of identifying healthy dietary habits that are feasible and sustainable. Three trials of a Mediterranean eating pattern reported modest weight loss and improved glycaemic control [66-68]. In one of these, people with new-onset diabetes assigned to a low-carbohydrate Mediterranean eating pattern were $37 \%$ less likely to require glucose-lowering medications over 4 years compared with patients assigned to a low-fat diet (HR 0.63; 95\% CI 0.51, 0.86). A meta-analysis of RCTs in patients with type 2 diabetes showed that the Mediterranean eating pattern reduced $\mathrm{HbA}_{1 \mathrm{c}}$ more than control diets (mean difference $-3.3 \mathrm{mmol} /$ $\mathrm{mol}, 95 \% \mathrm{CI}-5.1,-1.5 \mathrm{mmol} / \mathrm{mol}[-0.30 \%, 95 \% \mathrm{CI}-0.46 \%$, $-0.14 \%$ ]) [69]. Low-carbohydrate, low-glycaemic index and high-protein diets, and the Dietary Approaches to Stop Hypertension (DASH) diet all improve glycaemic control, but the effect of the Mediterranean eating pattern appears to be the greatest [70-72]. Low-carbohydrate diets $(<26 \%$ of total energy) produce substantial reductions in $\mathrm{HbA}_{1 \mathrm{c}}$ at 3 months $(-5.2 \mathrm{mmol} / \mathrm{mol}, 95 \% \mathrm{CI}-7.8,-2.5 \mathrm{mmol} / \mathrm{mol}$ $[-0.47 \%, 95 \% \mathrm{CI}-0.71 \%,-0.23 \%])$ and 6 months $(4.0 \mathrm{mmol} / \mathrm{mol}, 95 \% \mathrm{CI}-6.8,-1.0 \mathrm{mmol} / \mathrm{mol}[-0.36 \%$, $95 \% \mathrm{CI}-0.62 \%,-0.09 \%]$ ), with diminishing effects at 12 and 24 months; no benefit of moderate carbohydrate restriction (26-45\%) was observed [73]. Vegetarian eating patterns have been shown to lower $\mathrm{HbA}_{1 \mathrm{c}}$, but not fasting glucose, compared with non-vegetarian ones [74]. Very recent trials of different eating patterns in type 2 diabetes have typically also included weight reduction, hindering firm conclusions regarding the distinct contribution of dietary quality.

\section{Consensus recommendation}

All overweight and obese patients with diabetes should be advised of the health benefits of weight loss and encouraged to engage in a programme of intensive lifestyle management, which may include food substitution.

Non-surgical energy restriction for weight loss If a patient wishes to aim for remission of type 2 diabetes, particularly within 6 years of diagnosis, evidence-based weight management programmes are often successful.

The most effective non-surgical strategies for weight reduction involve food substitution and intensive, sustained counselling (e.g. 12-26 individual counselling sessions over 612 months). Among adults with type 2 diabetes, meal replacement (825-853 kcal/day [3450-3570 kj/day] formula-diet for
3-5 months) followed by gradual reintroduction of food and intensive counselling resulted in $9 \mathrm{~kg}$ placebo-adjusted weight loss at 1 year and high rates of diabetes remission (46\% vs 4\%; OR 19.7 ; $95 \%$ CI $7.8,49.8$ ) compared with best usual practice [75]. In terms of intensive behavioural interventions, the Action for Health in Diabetes (Look AHEAD) trial [76] randomised 5145 overweight or obese patients with type 2 diabetes to an intensive lifestyle programme that promoted energy restriction, incorporating meal replacements to induce and sustain weight loss, along with increased physical activity compared with standard diabetes education and support in the control group. After 9.6 years, weight loss was greater in the intervention group (8.6\% vs $0.7 \%$ at 1 year; $6.0 \%$ vs $3.5 \%$ at study end; both $p$ $<0.05)$. $\mathrm{HbA}_{1 \mathrm{c}}$ also fell in the intervention group despite less use of glucose-lowering medications. Cardiovascular event rates were not reduced but there were numerous other benefits. In a 12 month trial, 563 adults with type 2 diabetes who were randomised to Weight Watchers compared with standard care had a $2.1 \%$ net weight loss $(-4.0 \%$ vs $-1.9 \% ; p<0.001)$, a $5.3 \mathrm{mmol} / \mathrm{mol}(-3.5 \mathrm{vs}+1.8 \mathrm{mmol} / \mathrm{mol} ; p=0.020)$ net absolute improvement in $\mathrm{HbA}_{1 \mathrm{c}}(0.48 \%$ [ $-0.32 \%$ vs $\left.+0.16 \%]\right)$, and a greater reduction in use of glucose-lowering medications $(-26 \%$ vs $+12 \% ; p<0.001)$ [77]. Similar programmes have resulted in a net $3 \mathrm{~kg}$ weight loss over 12-18 months [78-80].

\section{Physical activity}

\section{Consensus recommendation}

Increasing physical activity improves glycaemic control and should be encouraged in all people with type 2 diabetes.

Aerobic exercise, resistance training, and the combination of the two are effective in reducing $\mathrm{HbA}_{1 \mathrm{c}}$ by about $6.6 \mathrm{mmol} /$ mol $(0.6 \%)$ [81-84]. Of these modalities, some evidence suggests that aerobic exercise and the combination of aerobic exercise and resistance training may be more effective than resistance training alone [85], but this remains controversial. When considering exercise interventions, special considerations are required for individuals with CVD, uncontrolled retinopathy or nephropathy and severe neuropathy. A wide range of physical activity, including leisure time activities (e.g. walking, swimming, gardening, jogging, tai chi and yoga) can significantly reduce $\mathrm{HbA}_{1 \mathrm{c}}$ [86-90]. In general, supervision of exercise and motivational strategies, such as monitoring using a step counter, can improve the effect of exercise on $\mathrm{HbA}_{1 \mathrm{c}}$ compared with advice alone [84, 91]. The combination of dietary change for weight reduction and physical exercise improves hyperglycaemia and reduces cardiovascular risk factors more than dietary interventions or physical activity alone [92]. 


\section{Medications for lowering glucose}

\section{Metformin}

Metformin is an oral medication that reduces plasma glucose via multiple mechanisms. It is available as an immediaterelease formulation that is typically administered twice a day and as extended-release formulations for once-daily or twicedaily administration. The formulations are equally effective with no consistent differences in side effect profile [93]. Dosages of immediate-release metformin start at $500 \mathrm{mg}$ once or twice a day with meals, and should be increased as tolerated to a target dosage of $1000 \mathrm{mg}$ twice a day. The maximum daily dose is $2550 \mathrm{mg}$ in the USA and $3000 \mathrm{mg}$ in the European Union, though doses above $2000 \mathrm{mg}$ are generally associated with little additional efficacy and poorer tolerability [94]. Gastrointestinal symptoms are common and dose-dependent, and may improve over time or with dose reduction. Metformin should not be used in patients with an eGFR $<30 \mathrm{ml} \mathrm{min}^{-1}$ $[1.73 \mathrm{~m}]^{-2}$ and dose reduction should be considered when the eGFR is $<45 \mathrm{ml} \mathrm{min}^{-1}$ [1.73 m] ${ }^{-2}$ [95-97]. Caution should be taken when conditions are present that may reduce eGFR. Advantages of metformin include its high efficacy, low cost, minimal hypoglycaemia risk when used as monotherapy, and the potential for some weight loss. Some studies have suggested a benefit for preventing CVD [98], but this has not been supported by the results of a recent meta-analysis [99]. However, metformin may lower risk for cardiovascular mortality compared with sulfonylurea therapy [100]. Rare cases of lactic acidosis have been reported, usually in the setting of severe illness or acute kidney injury. Therefore, metformin should be omitted in the setting of severe illness, vomiting or dehydration. Metformin may result in lower serum vitamin $\mathrm{B}_{12}$ concentration; therefore, periodic monitoring and supplementation is generally recommended if levels are deficient, particularly in those with anaemia or neuropathy [101]. Because of its high efficacy in lowering $\mathrm{HbA}_{1}$, good safety profile and low cost, metformin remains the first-line medication for management of type 2 diabetes.

\section{SGLT2 inhibitors}

SGLT2 inhibitors are oral medications that reduce plasma glucose by enhancing urinary excretion of glucose [102]. The glucose-lowering efficacy of these medications is dependent on renal function. Initiation and continuation of SGLT2 inhibitors are restricted by eGFR and require intermittent monitoring of renal function (refer to European Medicines Agency and US Food and Drug Administration prescribing information for current recommendations). These medications are of high efficacy in lowering glucose in the setting of normal renal function [51, 52, 103]. All SGLT2 inhibitors are associated with a reduction in weight and blood pressure. Alone or with metformin, they do not increase the risk for hypoglycaemia. Empagliflozin and canagliflozin have cardiac and renal benefits in patients with established or at high risk of ASCVD. Cardiac and renal benefits have been demonstrated down to an eGFR of $30 \mathrm{ml} \mathrm{min}^{-1}[1.73 \mathrm{~m}]^{-2}$, though currently none of the SGLT2 inhibitors have been approved for use by regula-

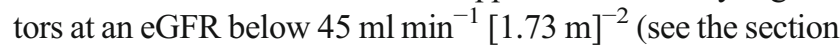
'Recommended process for glucose-lowering medication selection: where does new evidence from cardiovascular outcomes trials fit in?') $[51,52,61]$. The class is associated with increased risk for mycotic genital infections (mostly vaginitis in women, balanitis in men) [51, 52, 104, 105]. Case reports of diabetic ketoacidosis with SGLT2 inhibitors in type 2 diabetes continue to raise concern, though increased rates have not been confirmed in large trials $[102,106]$. Therefore, the SGLT2 inhibitors should be used with caution and appropriate patient education should be provided for those with insulin deficiency. SGLT2 inhibitors have been associated with an increased risk of acute kidney injury, dehydration and orthostatic hypotension; caution should be taken when SGLT2 inhibitors are used in combination with diuretics and/or ACE inhibitors and angiotensin receptor blockers. Canagliflozin has been associated with increased risk for lower limb amputation (6.3 canagliflozin vs 3.4 per 1000 patient-years with placebo after 3.1 years; HR 1.97; 95\% CI 1.41, 2.75;) [52]. Similarly, fracture risk has been reported with canagliflozin (15.4 vs 11.9 participants with fracture per 1000 patientyears; HR 1.26; 95\% CI 1.04, 1.52) [52]. It is uncertain whether amputation and fractures are class effects.

\section{GLP-1 receptor agonists}

GLP-1 receptor agonists are currently delivered by subcutaneous injection. These medications stimulate insulin secretion and reduce glucagon secretion in a glucose-dependent manner, improve satiety and promote weight loss [107, 108]. Structural differences among GLP-1 receptor agonists affect duration of action, and their formulation and dosing may affect efficacy for glucose-lowering and weight reduction as well as side effect profile and cardiovascular effects [109]. Dulaglutide, exenatide extended-release and semaglutide are administered once weekly [108, 109]. Liraglutide and lixisenatide are administered once daily, and exenatide is available in a twicedaily formulation. GLP-1 receptor agonists have high glucoselowering efficacy, but with variation within the drug class $[110,111]$. Evidence suggests that the effect may be greatest for semaglutide once weekly, followed by dulaglutide and liraglutide, closely followed by exenatide once weekly, and then exenatide twice daily and lixisenatide [110, 112-116]. The short-acting medications exenatide twice daily and lixisenatide have greater postprandial effects, at least after the meals with which they are administered. All GLP-1 receptor agonists reduce weight [110]; the reduction ranges from 
about $1.5 \mathrm{~kg}$ to $6.0 \mathrm{~kg}$ over about 30 weeks of therapy [110, 117]. Liraglutide and semaglutide have been shown to improve cardiovascular outcomes [47, 48] (see the section 'Recommended process for glucose-lowering medication selection: where does new evidence from cardiovascular outcomes trials fit in?'). The most common side effects of GLP1 receptor agonists are nausea, vomiting and diarrhoea, though these tend to diminish over time. GLP-1 receptor agonists have minimal risk for hypoglycaemia, but may increase the hypoglycaemic potential of insulin and sulfonylureas when combined with those medications [118]. Contrary to early signals, GLP-1 receptor agonists do not seem to substantially increase risk for pancreatitis, pancreatic cancer or bone disease [119]. They are associated with increased risk of gallbladder events [120]. Semaglutide was associated with increased retinopathy complications in the SUSTAIN 6 trial (HR 1.76, 95\% CI 1.11, 2.78), largely among those with baseline retinopathy who had rapid improvement of glycaemic control [48]. While this observation remains unexplained, this is also a recognised effect of intensification of glycaemic control with insulin.

\section{DPP-4 inhibitors}

DPP-4 inhibitors are oral medications that increase insulin secretion and reduce glucagon secretion in a glucose-dependent manner. They have moderate glucose-lowering efficacy [121, 122]. DPP-4 inhibitors are well tolerated, have a neutral effect on weight and have minimal risk of hypoglycaemia when used as monotherapy [123]. When added to sulfonylurea therapy, however, the risk for hypoglycaemia is increased $50 \%$ compared with sulfonylurea therapy alone [124]. The recommended dose for each DPP-4 inhibitor is determined and needs to be adjusted based on renal function; linagliptin is the exception as it has minimal renal excretion. Rare but increased rates of pancreatitis [125] and musculoskeletal side effects have been reported [126]. CVOTs demonstrated the cardiovascular safety but no cardiovascular benefit of three DPP-4 inhibitors (saxagliptin, alogliptin and sitagliptin) as well as imbalances regarding HF for saxagliptin and alogliptin $[127,128]$ (see the section 'Recommended process for glucose-lowering medication selection: where does new evidence from cardiovascular outcomes trials fit in?'.

\section{Thiazolidinediones}

Thiazolidinediones (TZDs) (pioglitazone and rosiglitazone) are oral medications that increase insulin sensitivity and are of high glucose-lowering efficacy [129-131]. TZDs increase HDL-cholesterol [132, 133], and pioglitazone has been shown to reduce cardiovascular endpoints $[132,134-138]$ and hepatic steatohepatitis [139], but without conclusive evidence for benefit. TZDs are associated with the best evidence among glucose-lowering medications for glycaemic durability
[140]. However, these notable benefits must be balanced with safety concerns regarding fluid retention and congestive heart failure [136, 140, 141], weight gain [132, 136, 140-142], bone fracture $[143,144]$ and, possibly, bladder cancer [145]. Lower dose therapy (e.g. pioglitazone 15-30 mg) mitigates weight gain and oedema, but the broader benefits and harms of low-dose TZD therapy have not been evaluated.

\section{Sulfonylureas}

Sulfonylureas are oral medications that lower glucose by stimulating insulin secretion from pancreatic beta cells. They are inexpensive, widely available, and have high glucoselowering efficacy [146]. Sulfonylureas were used as part of the glucose-lowering regimen in the UK Prospective Diabetes Study (UKPDS) [147] and Action in Diabetes and Vascular Disease: Preterax and Diamicron MR Controlled Evaluation (ADVANCE) [148] trials, which both demonstrated reductions in microvascular complications. Sulfonylureas are associated with weight gain and risk for hypoglycaemia and down titration of dose to reduce the risk of hypoglycaemia results in higher $\mathrm{HbA}_{1 \mathrm{c}}[146,149,150]$. Sulfonylureas are known to be associated with a lack of durable effect on glucose lowering $[144,151]$. The weight gain associated with sulfonylureas is relatively modest in large cohort studies and the incidence of severe hypoglycaemia is lower than with insulin [152]. Important differences among sulfonylureas affect both safety and efficacy. Glibenclamide (known as glyburide in the USA and Canada) has a higher risk of hypoglycaemia compared with other sulfonylureas [153]. Glipizide, glimepiride and gliclazide may have a lower risk for hypoglycaemia compared with other sulfonylureas $[152,154]$. Adverse cardiovascular outcomes with sulfonylureas in some observational studies have raised concerns, although findings from recent systematic reviews have found no increase in all-cause mortality compared with other active treatments [152]. As newergeneration sulfonylureas appear to confer a lower risk of hypoglycaemia and have favourable cost, efficacy and safety profiles, sulfonylureas remain a reasonable choice among glucose-lowering medications, particularly when cost is an important consideration. Patient education and use of low or variable dosing with later-generation sulfonylureas may be used to mitigate the risk of hypoglycaemia. Greatest caution in this regard is warranted for people at high risk of hypoglycaemia, such as older patients and those with CKD.

\section{Insulin}

Numerous formulations of insulin are available with differing durations of action. 'Human' insulins (NPH, regular [R], and premixed combinations of NPH and R) are recombinant DNA-derived human insulin, while insulin analogues have been designed to change the onset or duration of action. The 
main advantage of insulin over other glucose-lowering medications is that insulin lowers glucose in a dose-dependent manner over a wide range, to almost any glycaemic target as limited by hypoglycaemia. Older formulations of insulin have also demonstrated reduction in microvascular complications and with long-term follow-up, all-cause mortality and diabetes-related death [147, 155]. Beyond hypoglycaemia, the disadvantages of insulin include weight gain and the need for injection, frequent titration for optimal efficacy and glucose monitoring [156].

The effectiveness of insulin is highly dependent on its appropriate use; patient selection and training; adjustment of dose for changes in diet, activity or weight; and titration to acceptable, safe glucose targets. Formulations of intermediateand long-acting insulin have different timings of onset, durations of action and risks of hypoglycaemia. However, the way in which insulin is administered, including the dose, timing of injection and glycaemic targets, has a greater impact on the adverse effects of insulin than differences among insulin formulations.

Basal insulin Basal insulin refers to longer-acting insulin that is meant to cover the body's basal metabolic insulin requirement (regulating hepatic glucose production), in contrast to bolus or prandial insulin, which is meant to reduce glycaemic excursions after meals. Basal insulin is the preferred initial insulin formulation in patients with type 2 diabetes. Options include once- or twice-daily administration of intermediate-acting NPH or detemir insulin and the oncedaily administration of glargine (U100 or U300) or degludec (U100 or U200). Long-acting insulin analogues (degludec [U100 or U200], glargine [U100 and U300], detemir) have a modestly lower absolute risk for hypoglycaemia compared with NPH insulin, but cost more [157-160]. However, in real-world settings where patients are treated to conventional treatment targets, initiation of NPH compared with determir or glargine U100 did not increase hypoglycaemia-related emergency department visits or hospital admissions [161]. When comparing human and analogue insulins, cost differences can be large while differences in hypoglycaemia risk are modest and differences in glycaemic efficacy minimal.

Degludec is associated with a lower risk of severe hypoglycaemia compared with glargine U100 insulin when targeting intensive glycaemic control in patients with longstanding type 2 diabetes at high risk of CVD; absolute incidence difference of $1.7 \%$ over 2 years (rate ratio $0.60 ; p<$ 0.001 for superiority; OR $0.73 ; p<0.001$ for superiority) [162]. Biosimilar formulations are now available for glargine with similar efficacy profile and lower cost [163]. No insulin has been shown to reduce risk for CVD [156], but data suggest that glargine U100 and degludec do not increase risk for MACE $[162,164]$.
Concentrated formulations of degludec (U200) and glargine (U300) are available that allow injection of a reduced volume, a convenience for patients on higher doses. Glargine U300 is associated with a lower risk of nocturnal hypoglycaemia compared with glargine U100 but requires a $10-14 \%$ higher dose of glargine for equivalent efficacy [165-167].

Not all patients have their blood glucose adequately controlled with basal insulin. In particular, patients with higher pre-treatment $\mathrm{HbA}_{1 \mathrm{c}}$, higher BMI, longer duration of disease, and a greater number of oral glucose-lowering medications are more likely to require intensified therapy [168].

Other insulin formulations Short- and rapid-acting insulin formulations administered at mealtime are generally used to intensify basal insulin therapy in patients not meeting glycaemic targets. Options include human regular insulin, various analogues (aspart, glulisine and lispro), formulations (faster insulin aspart, lispro U200), biosimilars (lispro), and insulins with different routes of administration (inhaled). Rapid-acting insulin analogues have a modestly lower risk for hypoglycaemia compared with human regular insulin but at a higher cost. Various premixed formulations of human and analogue insulins are available and continue to be widely used in some regions, though they tend to have an increased risk of hypoglycemia as compared with basal insulin alone (Table 2 and Fig. 7).

\section{Other glucose-lowering medications}

Other oral glucose-lowering medications (i.e. meglitinides, $\alpha$-glucosidase inhibitors, colesevelam, quick-release bromocriptine, pramlintide) are not used commonly in the USA and some are not licensed at all in Europe. No major new scientific information on these medications has emerged in recent years. Their basic characteristics are listed in Table 2.

\section{Obesity management beyond lifestyle intervention}

\section{Medications for weight loss}

Several clinical practice guidelines recommend weight loss medications as an optional adjunct to intensive lifestyle management for patients with obesity, particularly if they have diabetes [169-171]. Others do not [172]. Several medications and medication combinations approved in the USA or Europe for weight loss have been found to improve glucose control in people with diabetes $[173,174]$. One glucose-lowering medication, liraglutide, is also approved for the treatment of obesity at a higher dose [175]. Cost, side effects and modest efficacy limit the role of pharmacotherapy in long-term weight management. 


\section{INTENSIFYING TO INJECTABLE THERAPIES}

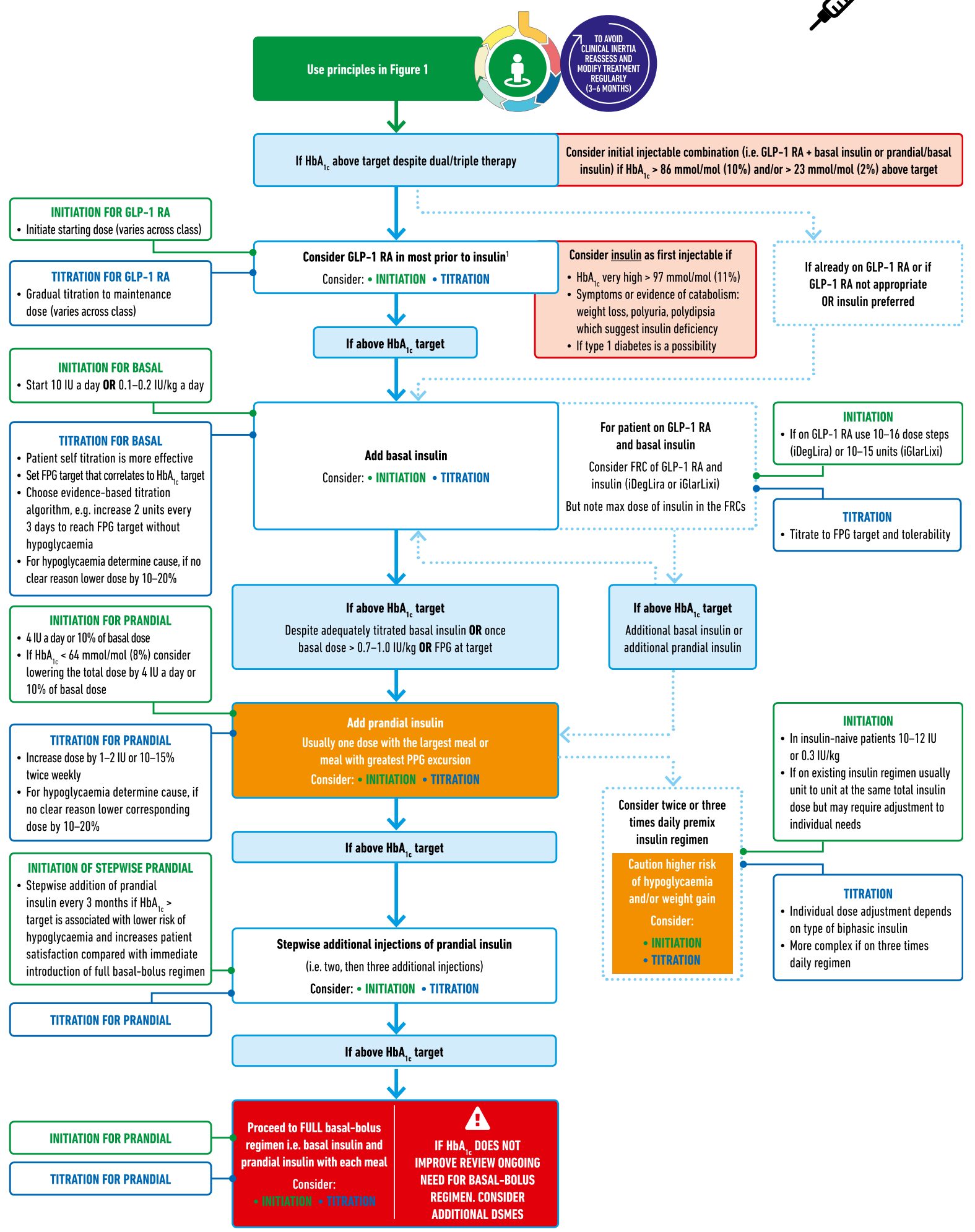

1. Consider choice of GLP-1 RA considering: patient preference, $\mathrm{HbA}_{1 \mathrm{C}}$ lowering, weight-lowering effect or frequency of injection. If CVD, consider GLP-1 RA with proven CVD benefit

FPG = Fasting Plasma Glucose

FRC = Fixed Ratio Combination

$\mathrm{PPG}=$ Post Prandial Glucose

Fig. 7 Intensifying to injectable therapies 


\section{Metabolic surgery}

\section{Consensus recommendation}

Metabolic surgery is a recommended treatment option for adults with type 2 diabetes and (1) a BMI $\geq 40.0$ $\mathrm{kg} / \mathrm{m}^{2}$ (BMI $\geq 37.5 \mathrm{~kg} / \mathrm{m}^{2}$ in people of Asian ancestry) or (2) a BMI of $35.0-39.9 \mathrm{~kg} / \mathrm{m}^{2}\left(32.5-37.4 \mathrm{~kg} / \mathrm{m}^{2}\right.$ in people of Asian ancestry) who do not achieve durable weight loss and improvement in comorbidities with reasonable non-surgical methods.

Metabolic surgery is highly effective in improving glucose control [176-178] and often produces disease remission [179-182]. The effects can be sustained for at least 5 years [177, 182]. Benefits include a reduction in the number of glucose-lowering medications needed to achieve glycaemic targets [178, 179].

Several clinical practice guidelines and position statements recommend consideration of metabolic surgery as a treatment option for adults with type 2 diabetes and (1) a BMI $\geq 40.0 \mathrm{~kg} /$ $\mathrm{m}^{2}$ (BMI $\geq 37.5 \mathrm{~kg} / \mathrm{m}^{2}$ in people of Asian ancestry) or (2) a BMI of $35.0-39.9 \mathrm{~kg} / \mathrm{m}^{2}\left(32.5-37.4 \mathrm{~kg} / \mathrm{m}^{2}\right.$ in people of Asian ancestry) who do not achieve durable weight loss and improvement in comorbidities with reasonable non-surgical methods [65, 183]. Because baseline BMI does not predict surgical benefits on glycaemia or hard outcomes and the improvement in glyacemic control occurs early through weightindependent mechanisms [183], metabolic surgery may be considered for those with a BMI of $30.0-34.9 \mathrm{~kg} / \mathrm{m}^{2}(27.5-$ 32.4 in people of Asian ancestry) who do not achieve durable weight loss and improvement in comorbidities with reasonable non-surgical methods.

Adverse effects of bariatric surgery which vary by procedure include surgical complications (e.g. anastomotic or staple line leaks, gastrointestinal bleeding, intestinal obstruction, the need for re-operation), late metabolic complications (e.g. protein malnutrition, mineral deficiency, vitamin deficiency, anaemia, hypoglycaemia) and gastroesophageal reflux [184, 185]. Patients who undergo metabolic surgery may be at risk for substance use, including drug and alcohol use and cigarette smoking [186]. People with diabetes presenting for metabolic surgery also have increased rates of depression and other major psychiatric disorders [187]. These factors should be assessed pre-operatively and during follow-up. Metabolic surgery should be performed in high-volume centres with multidisciplinary teams that are experienced in the management of diabetes and gastrointestinal surgery. Long-term lifestyle support and routine monitoring of micronutrient and nutritional status must be provided to patients after surgery [188, 189].

\section{Putting it all together: strategies for implementation}

For an increasing number of patients, presence of specific comorbidities (e.g. ASCVD, HF, CKD, obesity), safety concerns (e.g. risk of hypoglycaemia) or healthcare environment (e.g. cost of medications) mandate a specific approach to the choice of glucose-lowering medication. These are considered in Figs 2, 3, 4, 5, 6. For patients not reaching their target $\mathrm{HbA}_{1 \mathrm{c}}$, it is important to re-emphasise lifestyle measures, assess adherence and arrange timely follow-up (e.g. within 3-6 months) (Fig. 1).

\section{Initial monotherapy}

\section{Consensus recommendation}

Metformin is the preferred initial glucose-lowering medication for most people with type 2 diabetes.

Metformin remains the preferred option for initiating glucoselowering medication in type 2 diabetes and should be added to lifestyle measures in newly diagnosed patients. This recommendation is based on the efficacy, safety, tolerability, low cost and extensive clinical experience with this medication. Results from a substudy of the UKPDS $(n=342)$ showed benefits of initial treatment with metformin on clinical outcomes related to diabetes, with less hypoglycaemia and weight gain than with insulin or sulfonylureas [98].

\section{Initial combination therapy compared with stepwise addition of glucose-lowering medication}

\section{Consensus recommendation}

The stepwise addition of glucose-lowering medication is generally preferred to initial combination therapy.

In most patients, type 2 diabetes is a progressive disease, a consequence generally attributed to a steady decline of insulin secretory capacity. The practical impact of gradual loss of beta cell function is that achieving a glycaemic target with monotherapy is typically limited to several years. Stepwise therapy (i.e. adding medications to metformin to maintain $\mathrm{HbA}_{1 \mathrm{c}}$ at target) is supported by clinical trials [3]. While there is some support for initial combination therapy due to the greater initial reduction of $\mathrm{HbA}_{1 \mathrm{c}}$ than can be provided by metformin alone $[190,191]$, there is little evidence that this approach is superior to sequential addition of medications for maintaining glycaemic control, or slowing the progression of diabetes. However, since the absolute effectiveness of most oral medications rarely exceeds an $11 \mathrm{mmol} / \mathrm{mol}(1 \%)$ reduction in $\mathrm{HbA}_{1 \mathrm{c}}$, initial combination therapy may be considered in patients presenting with $\mathrm{HbA}_{1 \mathrm{c}}$ levels more than $17 \mathrm{mmol} / \mathrm{mol}$ (1.5\%) above their target. Fixed-dose formulations can improve medication adherence when combination therapy is used [192], and may help achieve glycaemic targets more rapidly [100]. Potential benefits of combination therapy need to be weighed against the exposure of patients to multiple 
medications and potential side effects, increased cost and, in the case of fixed combination medications, less flexibility in dosing.

\section{Choice of glucose-lowering medication after metformin}

\section{Consensus recommendation}

The selection of medication added to metformin is based on patient preference and clinical characteristics. Important clinical characteristics include the presence of established ASCVD and other comorbidities such as HF or CKD; the risk for specific adverse medication effects, particularly hypoglycaemia and weight gain; as well as safety, tolerability and cost (Figs 2-6).

As detailed in the 'Medications for lowering glucose' section, the glucose-lowering medications that can be added to metformin have distinct profiles of action, efficacy and adverse effects $[100,193]$. The early introduction of basal insulin is well established, in particular when $\mathrm{HbA}_{1 \mathrm{c}}$ levels are very high ( $>97 \mathrm{mmol} / \mathrm{mol}[>11 \%])$, symptoms of hyperglycaemia are present or there is evidence of ongoing catabolism (e.g. weight loss). This constellation of symptoms can occur in type 2 diabetes but suggest insulin deficiency and raise the possibility of autoimmune (type 1) or pancreatogenic diabetes in which insulin would be the preferred therapy. While this remains the usual strategy for patients when $\mathrm{HbA}_{1 \mathrm{c}}$ levels are very high, SGLT2 inhibitors [194] and GLP-1 receptor agonists [195] have demonstrated efficacy in patients with $\mathrm{HbA}_{1 \mathrm{c}}$ levels exceeding $75 \mathrm{mmol} / \mathrm{mol}$ (9\%), with the additional benefits of weight reduction and reduced risk of hypoglycaemia.

Evidence from clinical trials supports the use of several of the SGLT2 inhibitors and GLP-1 receptor agonists as add-on therapy for people with type 2 diabetes with an $\mathrm{HbA}_{1 \mathrm{c}}$ $>53 \mathrm{mmol} / \mathrm{mol}(>7 \%)$ and established CVD [48, 51, 52]. However, since only $15-20 \%$ of patients with type 2 diabetes conform to the characteristics of patients in these trials, other clinical features need to be considered in the majority when selecting second medications to add to metformin (Figs 2, 3, $4,5,6)$ [149, 196-204].

Sulfonylureas and insulin are associated with an increased risk for causing hypoglycaemia and would not be preferred for patients in whom this is a concern. Furthermore, hypoglycaemia is distressing and so may reduce treatment adherence (Fig. 5). For patients prioritizing weight loss or weight maintenance (Fig. 4), important considerations include the weight reduction associated with SGLT-2 inhibitors and GLP-1 receptor agonists, the weight neutrality of DPP-4 inhibitors, and the weight gain associated with sulfonylureas, basal insulin and TZDs. An important consideration for society in general and for many patients in particular is the cost of medications; sulfonylureas, pioglitazone and recombinant human insulins are relatively inexpensive, although their cost may vary across regions. Short-term acquisition costs, longer-term treatment cost and cost-effectiveness should be considered in clinical decision making when data are available (Fig. 6).

\section{Intensification beyond two medications}

\section{Consensus recommendation}

Intensification of treatment beyond dual therapy to maintain glycaemic targets requires consideration of the impact of medication side effects on comorbidities, as well as the burden of treatment and cost.

The lack of a substantial response to one or more non-insulin therapies should raise the issue of adherence and, in those with weight loss, the possibility that the patient has autoimmune (type 1) or pancreatogenic diabetes. However, it is common in people with long-standing diabetes to require more than two glucose-lowering agents, often including insulin. Compared with the knowledge base guiding dual therapy of type 2 diabetes, there is less evidence guiding these choices [205]. In general, intensification of treatment beyond two medications follows the same general principles as the addition of a second medication, with the assumption that the efficacy of third and fourth medications will be generally less than expected. No specific combination has demonstrated superiority except for those that include insulin and GLP-1 receptor agonists that have broad ranges of glycaemic efficacy. As more medications are added, there is an increased risk of adverse effects. It is important to consider medication interactions and whether regimen complexity may become an obstacle to adherence. Finally, with each additional medication comes increased costs, which can affect patient burden, medication-taking behaviour and medication effectiveness. [193, 205-211].

While most patients require intensification of glucoselowering medications, some require medication reduction or discontinuation of medication, particularly if the therapy is ineffective or is exposing patients to a higher risk of side effects such as hypoglycaemia, or when glycaemic goals have changed due to a change in clinical circumstances (e.g. development of comorbidities or even healthy ageing). A guiding principle is that for all therapies the response should be reviewed at regular intervals, including the impact on efficacy $\left(\mathrm{HbA}_{1 \mathrm{c}}\right.$, weight) and safety; the therapy should be stopped, or the dose reduced if there are minimal benefits or if harm outweighs any benefit. In particular, ceasing or reducing the dose of medications that have an increased risk of hypoglycaemia is important when any new glucose-lowering treatment (lifestyle or medication) is started (Fig. 7) [40]. $\mathrm{HbA}_{1 \mathrm{c}}$ levels below $48 \mathrm{mmol} /$ mol $(6.5 \%)$ or substantially below the individualised glycaemic target should prompt consideration of stopping 
or reducing the dose of medications with risk of hypoglycaemia or weight gain.

\section{Addition of injectable medications}

\section{Consensus recommendation}

In patients who need the greater glucose-lowering effect of an injectable medication, GLP-1 receptor agonists are the preferred choice to insulin. For patients with extreme and symptomatic hyperglycaemia, insulin is recommended (Fig. 7).

See the 'Insulin' and 'Basal insulin' sections in 'Medications for lowering glucose' for more medication details.

Patients often prefer combinations of oral medications to injectable medications. The range of combinations available with current oral medications allows many people to reach glycaemic targets safely. However, there is currently no evidence that any single medication or combination has durable effects and, for many patients, injectable medications become necessary within 5-10 years of diabetes diagnosis.

Evidence from trials comparing GLP-1 receptor agonists and insulin (basal, premixed or basal-bolus) shows similar or even better efficacy in $\mathrm{HbA}_{1 \mathrm{c}}$ reduction [212, 213]. GLP-1 receptor agonists have a lower risk of hypoglycaemia and are associated with reductions in body weight compared with weight gain with insulin $[212,214]$. Some GLP-1 receptor agonists allow for once weekly injections, as opposed to daily or more often for insulin. Based on these considerations, a GLP-1 receptor agonist is the preferred option in a patient with a definite diagnosis of type 2 diabetes who needs injectable therapy. However, the tolerability and high cost of GLP-1 receptor agonists are important limitations to their use. If additional glucose lowering is needed despite therapy with a long-acting GLP-1 receptor agonist, the addition of basal insulin is a reasonable option $[215,216]$.

Alternatively, the addition of insulin to oral medication regimens is well established. In particular, using basal insulin in combination with oral medications is effective, and has less hypoglycaemia and weight gain than combinations using premixed insulin formulations or prandial insulin [217]. A standard approach for optimising basal insulin regimens is to titrate the dose based on a target fasting glucose concentration, which is a simple index of effectiveness. Either NPH insulin or long-acting insulin analogues are efficacious for controlling fasting glucose, although basal analogue formulations show reduced risks of hypoglycaemia, particularly overnight, when titrated to the same fasting glucose target as NPH insulin [157, 218].

\section{Beyond basal insulin}

\section{Consensus recommendation}

Patients who are unable to maintain glycaemic targets on basal insulin in combination with oral medications can have treatment intensified with GLP-1 receptor agonists, SGLT2 inhibitors or prandial insulin (Figs 7 and 8).

It has become common practice to approach insulin use in people with type 2 diabetes by following the established paradigms developed for those with type 1 diabetes. This includes multiple daily injections with doses of insulin analogues before meals that are adjusted based on ambient blood glucose and meal constituents. While this is reasonable for people with type 2 diabetes who are lean, insulinopenic and sensitive to exogenous insulin, it ignores the substantial differences in pathophysiology between most people with type 2 diabetes and type 1 diabetes. Most people with type 2 diabetes are obese and insulin resistant, requiring much larger doses of insulin and experiencing lower rates of hypoglycaemia than those with type 1 diabetes. In patients with type 2 diabetes, weight gain is a particularly problematic side effect of insulin use. Recent evidence supports the effectiveness of combinations of insulin with glucose-lowering medications that do not increase body weight. For example, SGLT2 inhibitors can be added to insulin regimens to lower blood glucose levels without increasing insulin doses, weight gain or hypoglycaemia [219-221]. In a meta-analysis that studied the combination of either SGLT2 inhibitors or DPP-4 inhibitors with insulin, the SGLT2 inhibitor-insulin combination was associated with a greater reduction in $\mathrm{HbA}_{1 \mathrm{c}}$, an advantage in terms of body weight and no increase in the rates of hypoglycaemia [222, 223]. Depending on baseline $\mathrm{HbA}_{1 \mathrm{c}}$, glycaemic profile and individual response, the insulin dose may need to be reduced to prevent hypoglycaemia when adding an SGLT2 inhibitor.

The combination of basal insulin and a GLP-1 receptor agonist has high efficacy, with recent evidence from clinical trials demonstrating the benefits of this combination to lower $\mathrm{HbA}_{1 \mathrm{c}}$ and limit weight gain and hypoglycaemia compared with intensified insulin regimens [224, 225]. Most data come from studies in which a GLP-1 receptor agonist is added to basal insulin. However, there is evidence that insulin added to a GLP-1 receptor agonist can also effectively lower $\mathrm{HbA}_{1 \mathrm{c}}$, although some weight gain results [215]. Fixed-ratio combinations of insulin and GLP-1 receptor agonists are available and can decrease the number of injections compared with administering the medications separately [226-228].

A final approach to glycaemic management when basal insulin plus oral medications is insufficient to achieve $\mathrm{HbA}_{1 \mathrm{c}}$ targets is intensified insulin regimens (Figs 7 and 8). DSMES focused on insulin therapy is particularly helpful when intensified insulin therapy is considered. Referral to a 


\section{CONSIDERING ORAL THERAPY IN COMBINATION WITH INJECTABLE THERAPIES

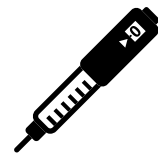 \\ METFORMIN \\ SGLT2i}

Continue treatment

with metformin

TZD'

Stop TZD when

commencing insulin

$O R$ reduce dose

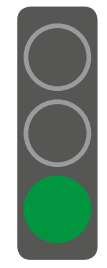

If on SGLT2i, continue

treatment

Consider adding SGLT2i if

- Established CVD

- If $\mathrm{HbA}_{1 \mathrm{c}}$ above

target or as weight

reduction aid

Beware

- DKA (euglycaemic)

- Instruct on sick-day rules

- Do not down-titrate

insulin over-aggressively

\section{SULFONYLUREA}

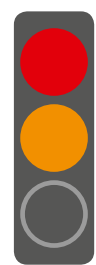

If on $\mathrm{SU}$, stop or reduce dose by $50 \%$ when

basal insulin initiated

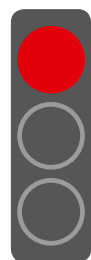

Consider stopping SU if

prandial insulin initiated

or on a premix regimen

\section{DPP-4i}

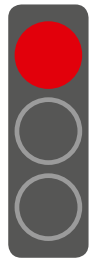

Stop DPP-4i if

GLP-1 RA initiated

1. Contraindicated in some countries, consider lower dose. This combination has a high risk of fluid retention and weight gain

Fig. 8 Considering oral therapy in combination with injectable therapies

diabetes specialist team should be considered in cases where the provider is uncomfortable or unfamiliar with intensification, poor outcomes continue despite intensification, or patients have other issues that complicate intensification. Intensified insulin regimens include (1) one or more daily injections of rapid- or short-acting insulin before meals (prandial insulin) or (2) switching to one to three daily administrations of a fixed combination of short- and long-acting insulin (premixed or biphasic insulins) [229, 230]. When adding prandial insulin, giving one injection with the largest meal of the day is a simple and safe approach [231]. Over time, if glycaemic targets are not met with one dose of prandial insulin daily, additional prandial injections can be added to other meals [232]. Results of meta-analyses suggest a modestly 
greater reduction in $\mathrm{HbA}_{1 \mathrm{c}}$ with basal-prandial regimens compared with biphasic insulin regimens, but at the expense of greater weight gain [233-235]. While still commonly used, we do not generally advocate premixed insulin regimens, particularly those administered three times daily, for routine use when intensifying insulin regimens (Fig. 7).

Continuous insulin infusion using insulin pumps may have a role in a small minority of people with type 2 diabetes [236].

\section{Access and cost}

\section{Consensus recommendation}

Access, treatment cost and insurance coverage should all be considered when selecting glucose-lowering medications.

The availability of glucose-lowering medications, patient support systems and blood glucose-monitoring devices can differ worldwide, depending on a region's economy, culture and healthcare system. Cost of and access to newer medications and insulin remain important issues throughout the world. Although the economics of diabetes care is complex and broadly includes the costs to society of diabetic complications and long-term outcomes, the cost of drugs and the affordability of treatment are often the primary basis for decision making. Within healthcare systems, variance in medication coverage is based on different assessments of cost-effectiveness. This results in huge disparities in the cost of new and old glucoselowering medications in some countries, limiting access to the full range of diabetes therapies in large segments of the population and creating a two-tiered system of treatment. Since glycaemic management remains a cornerstone of the prevention of diabetes complications, these disparities raise questions of fairness, equity and overall public health. Nonetheless, the use of less expensive agents, such as metformin, sulfonylureas and human insulin, remain effective options (Figs 2 and 6). Redoubling lifestyle management efforts can also have great impact, but behavioural intervention and support can also be costly, and socioeconomic barriers to improving lifestyle are well-described [237].

\section{Emerging technology}

There is an increasing call for the use of technology and telemedicine to improve patients' health [238]. Many types of inputs can be digitalised, such as blood glucose levels, time spent exercising, steps walked, energy ingested, medication doses administered, blood pressure and weight. Patterns in these variables can be identified by software, leading to specific treatment recommendations supported by real-time algorithms. Telemedicine incorporates multiple types of communication services, such as two-way video, email, texting, smartphones, tablets, wireless monitors, decision support tools and other forms of telecommunication technologies. Results overall suggest a modest improvement in glycaemic control [239, 240].

\section{Key knowledge gaps}

Despite over 200 years of research on lifestyle management of diabetes and more than 50 years of comparative-effectiveness research in diabetes, innumerable unanswered questions regarding the management of type 2 diabetes remain. In the context of our current consensus recommendations, the following is an incomplete discussion of vexing issues that must be addressed.

Evolving areas of current investigation will provide improvements in diabetes care and hold great hope for new treatments.

- Implementation science. The tools available to prevent and treat diabetes are vastly improved. However, implementation of effective innovation has lagged behind.

- Basic science. Our understanding of the basic mechanisms of diabetes, the development of complications, and the treatment of both, though continuously advancing, has highlighted how much we do not know.

- Personalised/precision medicine. Though promising, these -omics and big data approaches addressing both personal and environmental factors and their interaction are largely unrealised in diabetes care and will require large investments and coordination to have impact.

- Informatics. The benefits and role of enhanced monitoring of glucose and other variables leveraged with real-time informatics-based approaches to adapt treatment on an individual basis has great potential but has not been elucidated.

- Overweight/obesity. Current therapy is clearly inadequate. Innovation in methods and implementation would transform diabetes prevention and care. Understanding the biology, psychology and sociology of obesity to identify pharmacological, behavioural and political approaches to preventing and treating this principal cause of type 2 diabetes is essential.

- Lifestyle management and DSMES. Though the benefits of these approaches are clear, better paradigms on how to target, individualise and sustain the effects are needed.

- Beta-cell function. Preserving and enhancing beta cell function is perceived as the holy grail of diabetes and yet effective techniques are inadequately developed.

- Translational research. There is a huge gap between the knowledge gained from clinical trials and application of that information in clinical practice. This gap should be filled with pragmatic studies and other designs that include costs, measures of patient preference and other patientrecorded outcome measures. Patients and other 
stakeholders should have more input into trial designs and outcomes. Pragmatic designs will enhance generalisability of results and reduce cost. Better application of 'real-world evidence' will complement randomised trial evidence.

- Drug development. New medications will require demonstration of broad efficacy for glucose, comorbidities and/ or complications as well as safety and tolerability to compete in the marketplace.

- Complications. Steatohepatitis, HF, non-albuminuric $\mathrm{CKD}$, chronic mental illness and other emerging issues are complications in diabetes that may supplant classical microvascular and macrovascular disease in importance and impact. Understanding optimal diagnostic, screening and treatment strategies is urgently needed.

Other areas of importance include better segmentation of 'type 2 diabetes', as well as appropriate diagnosis of secondary diabetes, which should allow more informed individualisation of care. Better data on optimal approaches to diabetes management in frail and older adult patients is urgently required considering the controversy around glycaemic targets and the benefits and harms of specific treatments from lifestyle management to medications. Current approaches to the management of type 2 diabetes in adolescents and young adults do not seem to alter the loss of beta cell function and most individuals in this age group quickly transition to insulin therapy. Studies to guide optimal therapy in this emerging population with a terrifyingly high risk of early disability is an immediate need.

There are enduring questions that continue to challenge guideline development. For example, does metformin provide cardiovascular benefit in patients with type 2 diabetes early in the natural history of diabetes, as suggested by the UKPDS study? Is metformin's role as first-line medication management truly evidence-based or a quirk of history? Though the rationale for early combination therapy targeting normal levels of glycaemia in early diabetes is seductive, clinical trial evidence to support specific combinations and targets is essentially non-existent. As the cost implications for these approaches is enormous, evidence is desperately needed. Different models of care are being implemented globally. Defining optimal cost-effective approaches to care, particularly in the management of patients (multi-morbidity), is essential.

New questions arise from the recent cardiovascular outcomes studies. Do the cardiovascular and renal benefits of SGLT2 inhibitors and GLP-1 receptor agonists demonstrated in patients with established CVD extend to lower-risk patients? Is there additive benefit of use of GLP-1 receptor agonists and SGLT2 inhibitors for prevention of cardiovascular and renal events? If so, in what populations?

Addressing these and other vital clinical questions will require additional investment in basic, translational, clinical and implementation research. More time- and cost-efficient research paradigms to address patient-centred endpoints will need to be developed through regulatory reform and leveraging informatics and coordinated learning healthcare systems. The increasing burden of cardiorenal metabolic disease in terms of incidence, prevalence and cost is an existential threat to society. Urgent attention to improve prevention and treatment is of the essence.

The management of hyperglycaemia in type 2 diabetes has become extraordinarily complex with the number of glucoselowering medications now available. Patient-centred decision making and support and consistent efforts to improve diet and exercise remain the foundation of all glycaemic management. Initial use of metformin, followed by addition of glucoselowering medications based on patient comorbidities and concerns is recommended as we await answers to the many questions that remain.

Acknowledgements The authors would like to acknowledge Mindy Saraco (Associate Director, Scientific \& Medical Communication), Gedeon Topacio (Finance \& Project Manager, Research \& Scientific Programs) and Erika Berg (PhD, Director, Scientific and Medical Affairs) from the American Diabetes Association as well as Mary Hata (Executive Assistant) and Petra Niemann (Executive Assistant) from EASD for their help with the development of the consensus report and related meetings/presentations.

The authors would like to also acknowledge Mike Bonar (Creative Director) and Charlie Franklin (Design Assistant) from the Leicester Diabetes Centre, Leicester, UK, who provided considerable support in drafting and amending the figures. The authors also acknowledge Francesco Zaccardi (PhD, Clinical Research Fellow, University of Leicester, Leicester, UK) and David Kloecker (Medical Student, University of Leicester) who assisted with extracting PubMed articles and identifying relevant records by title and abstract; Francesco Zaccardi helped to define the initial search strategy and prepare the Excel file.

The authors acknowledge the invited peer reviewers who provided comments on an earlier draft of this report: Amanda Adler (Addenbrooke's Hospital, Cambridge, UK), Kåre I. Birkeland (University of Oslo, Oslo, Norway), James J. Chamberlain (St. Mark's Hospital, Salt Lake City, UT, USA), Jill P. Crandall (Albert Einstein College of Medicine, New York City, NY, USA), Ian H. de Boer (University of Washington, Seattle, WA, USA), Stefano Del Prato (University of Pisa, Pisa, Italy), George Dimitriadis (Athens University, Athens, Greece), Sean Dinneen (National University of Ireland, Galway, Ireland), Vivian A. Fonseca (Tulane University, New Orleans, LA, USA), Simon R. Heller (University of Sheffield, Sheffield, UK), Richard I. G. Holt (University of Southampton, Southampton, UK), Silvio E. Inzucchi (Yale University, New Haven, CT, USA), Eric L. Johnson (University of North Dakota, Grand Forks, ND, USA), Joshua J. Neumiller (Washington State University, Spokane, WA, USA), Kamlesh Khunti (University of Leicester, Leicester, UK), Harald H. Klein (Ruhr University of Bochum, Bochum, Germany), Line Kleinebreil (Hôpital national de Saint Maurice, Saint-Maurice, France), José Manuel Fernández-Real (Universitat de Girona, Girona, Spain), Sally M. Marshall (Newcastle University, Newcastle upon Tyne, UK), Manel Mata-Cases (Institut Universitari d'Investigació en Atenció Primària Jordi Gol [IDIAP Jordi Gol], Barcelona, Spain), David R. Matthews (University of Oxford, Oxford, UK), David M. Nathan (Massachusetts General Hospital, Boston, MA, USA), Michael A. Nauck (Diabetes Center Bochum-Hattingen, St Josef-Hospital, RuhrUniversity, Bochum, Germany), Frank Nobels (OLV-Hospital, Aalst, Belgium), Richard E. Pratley (Florida Hospital Diabetes Institute, Orlando, FL, USA), Maria Jose Redondo (Baylor College of Medicine, Houston, TX, USA), Michael R. Rickels (University of Pennsylvania, Philadelphia, PA, USA), Matthew C. Riddle (Oregon Health \& Science University, Portland, OR, USA), Julio Rosenstock (Diabetes and Endocrine Center, Dallas, TX, 
USA), Giorgio Sesti (Magna Graecia University of Catanzaro, Catanzaro, Italy), Neil Skolnik (Abington Family Medicine, Jenkintown, PA, USA), Krzysztof Strojek (Silesian Medical University, Zabrze, Poland), Jennifer Trujillo (University of Colorado, Denver, CO, USA), Guillermo E. Umpierrez (Emory University, Atlanta, GA, USA) and Jennifer Wyckoff (University of Michigan, Ann Arbor, MI, USA).

Data availability The details of the search strategy, the results and the classification for the included articles are available at https://doi.org/10. 17632/h5rcnxpk8w.1.

Funding This activity was funded by the American Diabetes Association and the European Association for the Study of Diabetes.

Duality of interest M. J. Davies reports personal fees and grants from Boehringer Ingelheim, Janssen, Novo Nordisk and Sanofi and personal fees from AstraZeneca, Eli Lilly, Gilead Sciences Ltd., Intarcia/Servier, Merck Sharp \& Dohme, Mitsubishi Tanabe Pharma Corporation and Takeda Pharmaceuticals International Inc.

D. D'Alessio reports personal fees from Eli Lilly, Merck, Novo Nordisk, and Intarcia, and grants from Merck, and Ligand during the conduct of the study; personal fees from Eli Lilly, Merck, Novo Nordisk, and Intarcia, and grants from Merck, and Ligand outside the submitted work.

J. Fradkin has nothing to disclose. J. Fradkin's input into this consensus report is from her own perspective and the Report does not reflect the view of the National Institutes of Health, Department of Health and Human Services or the US Government.

W. N. Kernan has nothing to disclose.

C. Mathieu reports grants and personal fees from Novo Nordisk, grants and personal fees from Sanofi, grants and personal fees from Merck Sharp \& Dohme Ltd., grants and personal fees from Eli Lilly and Company, grants and personal fees from Novartis, personal fees from Bristol-Myers Squibb, personal fees from AstraZeneca, grants and personal fees from Boehringer Ingelheim, personal fees from Hanmi Pharmaceuticals, grants and personal fees from Roche Diagnostics, grants and personal fees from Medtronic, grants and personal fees from Intrexon, grants and personal fees from Abbott, and personal fees from UCB, outside the submitted work.

G Mingrone reports grants and personal fees from Novo Nordisk, personal fees from Johnson \& Johnson, personal fees from Fractyl Inc., during the conduct of the study.

P. Rossing reports grants, non-financial support and other from Novo Nordisk, grants and other from AstraZeneca, other from Bayer, other from Boehringer Ingelheim, other from MSD, other from Eli Lilly, during the conduct of the study.

A. Tsapas reports non-financial support from the European Association for the Study of Diabetes, during the conduct of the study; grants and other from Boehringer Ingelheim, grants and other from Novo Nordisk, other from Novartis, grants and other from Sanofi, grants and other from AstraZeneca, grants from GSK, grants and other from European Foundation for the Study of Diabetes (EFSD), outside the submitted work.

D. J. Wexler has nothing to disclose.

J. B. Buse has provided consultation to Adocia, AstraZeneca, Eli Lilly, GI Dynamics, Intarcia, MannKind, NovaTarg, Novo Nordisk, Senseonics, and vTv Therapeutics with fees paid to the University of North Carolina. He has received grant support from AstraZeneca, Johnson \& Johnson, Novo Nordisk, Sanofi, and vTv Therapeutics. He is a consultant to Neurimmune AG. He holds stock options in Mellitus Health, PhaseBio and Stability Health. He is supported by a grant from the National Institutes of Health (UL1TR002489).

Contribution statement All authors were responsible for drafting the article and revising it critically for important intellectual content. All authors approved the version to be published.

\section{References}

1. Rodriguez-Gutierrez R, Gionfriddo MR, Ospina NS et al (2016) Shared decision making in endocrinology: present and future directions. Lancet Diabetes Endocrinol 4:706-716. https://doi.org/ 10.1016/S2213-8587(15)00468-4

2. American Diabetes Association (2018) 6. Glycemic targets: standards of medical care in diabetes-2018. Diabetes Care 41:S55S64. https://doi.org/10.2337/dc18-S006

3. American Diabetes Association (2018) 8. Pharmacologic approaches to glycemic treatment: standards of medical care in diabetes-2018. Diabetes Care 41:S73-S85. https://doi.org/10.2337/ dc18-S008

4. Inzucchi SE, Bergenstal RM, Buse JB et al (2012) Management of hyperglycaemia in type 2 diabetes: a patient-centered approach. Position statement of the American Diabetes Association (ADA) and the European Association for the Study of Diabetes (EASD). Diabetologia 55:1577-1596

5. Inzucchi SE, Bergenstal RM, Buse JB et al (2015) Management of hyperglycaemia in type 2 diabetes, 2015: a patient-centered approach. Update to a position statement of the American Diabetes Association and the European Association for the Study of Diabetes. Diabetologia 58:429-442. https://doi.org/10.2337/ dc14-2441

6. Riddle MC, Gerstein HC, Holman RR et al (2018) A1C targets should be personalized to maximize benefits while limiting risks. Diabetes Care 41:1121-1124. https://doi.org/10.2337/dci18-0018

7. American Diabetes Association (2018) 9. Cardiovascular disease and risk management: standards of medical care in diabetes-2018. Diabetes Care 41:S86-S104. https://doi.org/10. 2337/dc18-S009

8. Gæde P, Oellgaard J, Carstensen B et al (2016) Years of life gained by multifactorial intervention in patients with type 2 diabetes mellitus and microalbuminuria: 21 years follow-up on the Steno2 randomised trial. Diabetologia 59:2298-2307. https://doi.org/ 10.1007/s00125-016-4065-6

9. Khunti K, Kosiborod M, Ray KK (2018) Legacy benefits of blood glucose, blood pressure and lipid control in individuals with diabetes and cardiovascular disease: time to overcome multifactorial therapeutic inertia? Diabetes Obes Metab 20:1337-1341. https:// doi.org/10.1111/dom. 13243

10. Gregg EW, Sattar N, Ali MK (2016) The changing face of diabetes complications. Lancet Diabetes Endocrinol 4:537-547. https:// doi.org/10.1016/S2213-8587(16)30010-9

11. Little RR, Rohlfing CL, Sacks DB (2011) Status of $\mathrm{HbA}_{1 \mathrm{c}}$ measurement and goals for improvement: from chaos to order for improving diabetes care. Clin Chem 57:204-214

12. American Diabetes Association (2018) 2. Classification and diagnosis of diabetes: standards of medical care in diabetes-2018. Diabetes Care 41:S13-S27. https://doi.org/10.2337/dc18-S002

13. Mannucci E, Antenore A, Giorgino F, Scavini M (2018) Effects of structured versus unstructured self-monitoring of blood glucose on glucose control in patients with non-insulin-treated type 2 diabetes: a meta-analysis of randomized controlled trials. J Diabetes Sci Technol 12:183-189. https://doi.org/10.1177/1932296817719290

14. Young LA, Buse JB, Weaver MA et al (2017) Glucose selfmonitoring in non-insulin-treated patients with type 2 diabetes in primary care settings: a randomized trial. JAMA Intern Med 177:920-929. https://doi.org/10.1001/jamainternmed.2017.1233

15. Anjana RM, Kesavadev J, Neeta D et al (2017) A multicenter reallife study on the effect of flash glucose monitoring on glycemic control in patients with type 1 and type 2 diabetes. Diabetes Technol Ther 19:533-540 
16. American Diabetes Association (2018) 3. Comprehensive medical evaluation and assessment of comorbidities: standards of medical care in diabetes-2018. Diabetes Care 41:S28-S37. https://doi. org/10.2337/dc18-S003

17. Kunneman M, Montori VM, Castaneda-Guarderas A, Hess EP (2016) What is shared decision making? (and what it is not). Acad Emerg Med 23:1320-1324. https://doi.org/10.1111/acem. 13065

18. Breslin M, Mullan RJ, Montori VM (2008) The design of a decision aid about diabetes medications for use during the consultation with patients with type 2 diabetes. Patient Educ Couns 73:465472. https://doi.org/10.1016/j.pec.2008.07.024

19. Mullan RJ, Montori VM, Shah ND et al (2009) The diabetes mellitus medication choice decision aid: a randomized trial. Arch Intern Med 169:1560-1568. https://doi.org/10.1001/ archinternmed.2009.293

20. Stacey D, Légaré F, Lewis K et al (2017) Decision aids for people facing health treatment or screening decisions. Cochrane Database Syst Rev 4:CD001431. https://doi.org/10.1002/14651858. CD001431.pub5

21. American Diabetes Association (2018) 4. Lifestyle management: standards of medical care in diabetes-2018. Diabetes Care 41: S38-S50. https://doi.org/10.2337/dc18-S004

22. Powers MA, Bardsley J, Cypress M et al (2015) Diabetes selfmanagement education and support in type 2 diabetes: a joint position statement of the American Diabetes Association, the American Association of Diabetes Educators, and the Academy of Nutrition and Dietetics. Diabetes Care 38:1372-1382. https:// doi.org/10.2337/dc15-0730

23. Department of Health; Diabetes UK (2005) Structured patient education in diabetes: report from the Patient Education Working Group. Available from http://webarchive.nationalarchives.gov. uk/20130105204013/http://www.dh.gov.uk/en/ Publicationsandstatistics/Publications/PublicationsPolicy AndGuidance/DH_4113195. Accessed 29 Aug 2018

24. National Institute for Health and Clinical Excellence (2011) Quality standard for diabetes in adults, statements 2 and 3. Available from https://www.nice.org.uk/guidance/qs6. Accessed 29 Aug 2018

25. Beck J, Greenwood DA, Blanton L et al (2017) 2017 national standards for diabetes self-management education and support. Diabetes Educ 43:449-464

26. Chrvala CA, Sherr D, Lipman RD (2016) Diabetes selfmanagement education for adults with type 2 diabetes mellitus: a systematic review of the effect on glycemic control. Patient Educ Couns 99:926-943. https://doi.org/10. 1016/j.pec.2015.11.003

27. Pillay J, Armstrong MJ, Butalia S et al (2015) Behavioral programs for type 2 diabetes mellitus: a systematic review and network meta-analysis. Ann Intern Med 163:848. https://doi.org/10. 7326/M15-1400

28. Zhao F-F, Suhonen R, Koskinen S, Leino-Kilpi H (2017) Theorybased self-management educational interventions on patients with type 2 diabetes: a systematic review and meta-analysis of randomized controlled trials. J Adv Nurs 73:812-833. https://doi.org/10. 1111/jan. 13163

29. Odgers-Jewell K, Ball LE, Kelly JT et al (2017) Effectiveness of group-based self-management education for individuals with type 2 diabetes: a systematic review with meta-analyses and meta-regression. Diabet Med 34:1027-1039. https://doi.org/10.1111/dme. 13340

30. He X, Li J, Wang B et al (2017) Diabetes self-management education reduces risk of all-cause mortality in type 2 diabetes patients: a systematic review and meta-analysis. Endocrine 55:712731. https://doi.org/10.1007/s12020-016-1168-2
31. Chatterjee S, Davies MJ, Heller S et al (2018) Diabetes structured self-management education programmes: a narrative review and current innovations. Lancet Diabetes Endocrinol 6:130-142. https://doi.org/10.1016/S2213-8587(17)30239-5

32. Egede LE, Gebregziabher M, Echols C, Lynch CP (2014) Longitudinal effects of medication nonadherence on glycemic control. Ann Pharmacother 48:562-570. https://doi.org/10.1177/ 1060028014526362

33. Huber CA, Reich O (2016) Medication adherence in patients with diabetes mellitus: does physician drug dispensing enhance quality of care? Evidence from a large health claims database in Switzerland. Patient Prefer Adherence 10:1803-1809. https://doi. org/10.2147/PPA.S115425

34. Iglay K, Cartier SE, Rosen VM et al (2015) Meta-analysis of studies examining medication adherence, persistence, and discontinuation of oral antihyperglycemic agents in type 2 diabetes. Curr Med Res Opin 31:1283-1296. https://doi.org/10.1185/03007995. 2015.1053048

35. McGovern A, Tippu Z, Hinton W et al (2016) Systematic review of adherence rates by medication class in type 2 diabetes: a study protocol. BMJ Open 6:e010469. https://doi.org/10.1136/bmjopen2015-010469

36. Khunti K, Seidu S, Kunutsor S, Davies M (2017) Association between adherence to pharmacotherapy and outcomes in type 2 diabetes: a meta-analysis. Diabetes Care 40:1588-1596. https:// doi.org/10.2337/dc16-1925

37. Polonsky WH, Henry RR (2016) Poor medication adherence in type 2 diabetes: recognizing the scope of the problem and its key contributors. Patient Prefer Adherence 10:1299-1307. https://doi. org/10.2147/PPA.S106821

38. McGovern A, Tippu Z, Hinton W et al (2018) Comparison of medication adherence and persistence in type 2 diabetes: a systematic review and meta-analysis. Diabetes Obes Metab 20:1040 1043. https://doi.org/10.1111/dom.13160

39. Lasalvia P, Barahona-Correa JE, Romero-Alvernia DM et al (2016) Pen devices for insulin self-administration compared with needle and vial: systematic review of the literature and meta-analysis. J Diabetes Sci Technol 10:959-966. https://doi.org/10.1177/ 1932296816633721

40. Khunti K, Davies MJ (2017) Clinical inertia - time to reappraise the terminology? Prim Care Diabetes 11:105-106. https://doi.org/ 10.1016/j.pcd.2017.01.007

41. Furler J, O'Neal D, Speight J et al (2017) Supporting insulin initiation in type 2 diabetes in primary care: results of the Stepping Up pragmatic cluster randomised controlled clinical trial. BMJ:j783. https://doi.org/10.1136/bmj.j783

42. Manski-Nankervis J-A, Furler J, O'Neal D et al (2017) Overcoming clinical inertia in insulin initiation in primary care for patients with type 2 diabetes: 24-month follow-up of the Stepping Up cluster randomised controlled trial. Prim Care Diabetes 11:474-481. https://doi.org/10.1016/j.pcd.2017.06.005

43. Tabesh M, Magliano DJ, Koye DN, Shaw JE (2018) The effect of nurse prescribers on glycaemic control in type 2 diabetes: a systematic review and meta-analysis. Int J Nurs Stud 78:37-43. https://doi.org/10.1016/j.ijnurstu.2017.08.018

44. Murphy ME, Byrne M, Galvin R et al (2017) Improving risk factor management for patients with poorly controlled type 2 diabetes: a systematic review of healthcare interventions in primary care and community settings. BMJ Open 7:e015135. https://doi. org/10.1136/bmjopen-2016-015135

45. American Diabetes Association (2018) 1. Improving care and promoting health in populations: standards of medical care in diabetes-2018. Diabetes Care 41:S7-S12. https://doi.org/10.2337/ dc18-S001

46. Cefalu WT, Kaul S, Gerstein HC et al (2018) Cardiovascular outcomes trials in type 2 diabetes: where do we go from here? 
Reflections from a Diabetes Care Editors' Expert Forum. Diabetes Care 41:14-31. https://doi.org/10.2337/dci17-0057

47. Marso SP, Daniels GH, Brown-Frandsen K et al (2016) Liraglutide and cardiovascular outcomes in type 2 diabetes. N Engl J Med 375:311-322. https://doi.org/10.1056/NEJMoa1603827

48. Marso SP, Bain SC, Consoli A et al (2016) Semaglutide and cardiovascular outcomes in patients with type 2 diabetes. N Engl J Med 375:1834-1844. https://doi.org/10.1056/NEJMoa1607141

49. Holman RR, Bethel MA, Mentz RJ et al (2017) Effects of onceweekly exenatide on cardiovascular outcomes in type 2 diabetes. N Eng1 J Med 377:1228-1239. https://doi.org/10.1056/ NEJMoa1612917

50. Pfeffer MA, Claggett B, Diaz R et al (2015) Lixisenatide in patients with type 2 diabetes and acute coronary syndrome. N Engl J Med 373:2247-2257. https://doi.org/10.1056/NEJMoa1509225

51. Zinman B, Wanner C, Lachin JM et al (2015) Empagliflozin, cardiovascular outcomes, and mortality in type 2 diabetes. N Engl J Med 373:2117-2128. https://doi.org/10.1056/NEJMoa1504720

52. Neal B, Perkovic V, Mahaffey KW et al (2017) Canagliflozin and cardiovascular and renal events in type 2 diabetes. N Engl J Med 377:644-657. https://doi.org/10.1056/NEJMoa1611925

53. Lehrke M, Marx N (2017) Diabetes mellitus and heart failure. Am J Med 130:S40-S50. https://doi.org/10.1016/j.amjmed.2017.04. 010

54. Fitchett D, Zinman B, Wanner C et al (2016) Heart failure outcomes with empagliflozin in patients with type 2 diabetes at high cardiovascular risk: results of the EMPA-REG OUTCOME® trial. Eur Heart J 37:1526-1534. https://doi.org/10.1093/eurheartj/ ehv728

55. Rådholm K, Figtree G, Perkovic V et al (2018) Canagliflozin and heart failure in type 2 diabetes mellitus: results from the CANVAS Program (Canagliflozin Cardiovascular Assessment Study). Circulation 138:458-468. https://doi.org/10.1161/ CIRCULATIONAHA.118.034222

56. Margulies KB, Hernandez AF, Redfield MM et al (2016) Effects of liraglutide on clinical stability among patients with advanced heart failure and reduced ejection fraction: a randomized clinical trial. JAMA 316:500-508. https://doi.org/10.1001/jama.2016. 10260

57. Jorsal A, Kistorp C, Holmager P et al (2017) Effect of liraglutide, a glucagon-like peptide-1 analogue, on left ventricular function in stable chronic heart failure patients with and without diabetes (LIVE)-a multicentre, double-blind, randomised, placebocontrolled trial. Eur J Heart Fail 19:69-77. https://doi.org/10. 1002/ejhf.657

58. Scirica BM, Bhatt DL, Braunwald E et al (2013) Saxagliptin and cardiovascular outcomes in patients with type 2 diabetes mellitus. N Engl J Med 369:1317-1326. https://doi.org/10.1056/ NEJMoa1307684

59. White WB, Cannon CP, Heller SR et al (2013) Alogliptin after acute coronary syndrome in patients with type 2 diabetes. N Engl J Med 369:1327-1335. https://doi.org/10.1056/NEJMoa1305889

60. Green JB, Bethel MA, Armstrong PW et al (2015) Effect of sitagliptin on cardiovascular outcomes in type 2 diabetes. $\mathrm{N}$ Engl J Med 373:232-242. https://doi.org/10.1056/NEJMoa1501352

61. Wanner C, Inzucchi SE, Lachin JM et al (2016) Empagliflozin and progression of kidney disease in type 2 diabetes. N Engl J Med 375:323-334. https://doi.org/10.1056/NEJMoa1515920

62. Jardine MJ, Mahaffey KW, Neal B et al (2017) The Canagliflozin and Renal Endpoints in Diabetes with Established Nephropathy Clinical Evaluation (CREDENCE) study rationale, design, and baseline characteristics. Am J Nephrol 46:462-472. https://doi. org/10.1159/000484633

63. Mann JFE, Ørsted DD, Brown-Frandsen K et al (2017) Liraglutide and renal outcomes in type 2 diabetes. N Engl J Med 377:839-848. https://doi.org/10.1056/NEJMoa1616011
64. Deacon CF (2018) A review of dipeptidyl peptidase-4 inhibitors. Hot topics from randomized controlled trials. Diabetes Obes Metab 20(Suppl 1):34-46. https://doi.org/10.1111/dom.13135

65. American Diabetes Association (2018) 7. Obesity management for the treatment of type 2 diabetes: standards of medical care in diabetes-2018. Diabetes Care 41:S65-S72. https://doi.org/10. 2337/dc18-S007

66. Shai I, Schwarzfuchs D, Henkin Y et al (2008) Weight loss with a low-carbohydrate, Mediterranean, or low-fat diet. N Engl J Med 359:229-241. https://doi.org/10.1056/NEJMoa0708681

67. Esposito K, Maiorino MI, Ciotola M et al (2009) Effects of a Mediterranean-style diet on the need for antihyperglycemic drug therapy in patients with newly diagnosed type 2 diabetes: a randomized trial. Ann Intern Med 151:306-314

68. Esposito K, Maiorino MI, Petrizzo M et al (2014) The effects of a Mediterranean diet on the need for diabetes drugs and remission of newly diagnosed type 2 diabetes: follow-up of a randomized trial. Diabetes Care 37:1824-1830. https://doi.org/10.2337/dc13-2899

69. Huo R, Du T, Xu Y et al (2015) Effects of Mediterranean-style diet on glycemic control, weight loss and cardiovascular risk factors among type 2 diabetes individuals: a meta-analysis. Eur J Clin Nutr 69:1200-1208. https://doi.org/10.1038/ejen.2014.243

70. Snorgaard O, Poulsen GM, Andersen HK, Astrup A (2017) Systematic review and meta-analysis of dietary carbohydrate restriction in patients with type 2 diabetes. BMJ Open Diabetes Res Care 5:e000354. https://doi.org/10.1136/bmjdrc-2016-000354

71. Ajala O, English P, Pinkney J (2013) Systematic review and metaanalysis of different dietary approaches to the management of type 2 diabetes. Am J Clin Nutr 97:505-516. https://doi.org/10.3945/ ajcn.112.042457

72. Azadbakht L, Fard NRP, Karimi M et al (2011) Effects of the Dietary Approaches to Stop Hypertension (DASH) eating plan on cardiovascular risks among type 2 diabetic patients: a randomized crossover clinical trial. Diabetes Care 34:55-57. https://doi. org/10.2337/dc10-0676

73. Sainsbury E, Kizirian NV, Partridge SR et al (2018) Effect of dietary carbohydrate restriction on glycemic control in adults with diabetes: a systematic review and meta-analysis. Diabetes Res Clin Pract 139:239-252. https://doi.org/10.1016/j.diabres.2018. 02.026

74. Yokoyama Y, Barnard ND, Levin SM, Watanabe M (2014) Vegetarian diets and glycemic control in diabetes: a systematic review and meta-analysis. Cardiovasc Diagn Ther 4:373-382. https://doi.org/10.3978/j.issn.2223-3652.2014.10.04

75. Lean ME, Leslie WS, Barnes AC et al (2018) Primary care-led weight management for remission of type 2 diabetes (DiRECT): an open-label, cluster-randomised trial. Lancet 391:541-551. https://doi.org/10.1016/S0140-6736(17)33102-1

76. Look AHEAD Research Group, Wing RR, Bolin P et al (2013) Cardiovascular effects of intensive lifestyle intervention in type 2 diabetes. N Engl J Med 369:145-154. https://doi.org/10.1056/ NEJMoa1212914

77. O’Neil PM, Miller-Kovach K, Tuerk PW et al (2016) Randomized controlled trial of a nationally available weight control program tailored for adults with type 2 diabetes. Obes Silver Spring Md 24:2269-2277. https://doi.org/10.1002/oby. 21616

78. Jebb SA, Ahern AL, Olson AD et al (2011) Primary care referral to a commercial provider for weight loss treatment versus standard care: a randomised controlled trial. Lancet 378:1485-1492. https://doi.org/10.1016/S0140-6736(11)61344-5

79. Leblanc ES, O'Connor E, Whitlock EP et al (2011) Effectiveness of primary care-relevant treatments for obesity in adults: a systematic evidence review for the U.S. Preventive Services Task Force. Ann Intern Med 155:434-447. https://doi.org/10.7326/00034819-155-7-201110040-00006 
80. Delahanty LM, Dalton KM, Porneala B et al (2015) Improving diabetes outcomes through lifestyle change - a randomized controlled trial. Obes Silver Spring Md 23:1792-1799. https://doi.org/ 10.1002/oby. 21172

81. Boulé NG, Haddad E, Kenny GP et al (2001) Effects of exercise on glycemic control and body mass in type 2 diabetes mellitus: a meta-analysis of controlled clinical trials. JAMA 286:1218-1227

82. Chudyk A, Petrella RJ (2011) Effects of exercise on cardiovascular risk factors in type 2 diabetes: a meta-analysis. Diabetes Care 34:1228-1237. https://doi.org/10.2337/dc10-1881

83. Yang Z, Scott CA, Mao C et al (2014) Resistance exercise versus aerobic exercise for type 2 diabetes: a systematic review and metaanalysis. Sports Med Auckl NZ 44:487-499. https://doi.org/10. 1007/s40279-013-0128-8

84. Balducci S, Zanuso S, Nicolucci A et al (2010) Effect of an intensive exercise intervention strategy on modifiable cardiovascular risk factors in subjects with type 2 diabetes mellitus: a randomized controlled trial: the Italian Diabetes and Exercise Study (IDES). Arch Intern Med 170:1794-1803. https://doi.org/10.1001/ archinternmed.2010.380

85. Schwingshackl L, Missbach B, Dias S et al (2014) Impact of different training modalities on glycaemic control and blood lipids in patients with type 2 diabetes: a systematic review and network meta-analysis. Diabetologia 57:1789-1797. https://doi.org/10. 1007/s00125-014-3303-z

86. Qiu S, Cai X, Schumann U et al (2014) Impact of walking on glycemic control and other cardiovascular risk factors in type 2 diabetes: a meta-analysis. PLoS One 9:e109767. https://doi.org/ 10.1371/journal.pone.0109767

87. Rees JL, Johnson ST, Boulé NG (2017) Aquatic exercise for adults with type 2 diabetes: a meta-analysis. Acta Diabetol 54: 895-904. https://doi.org/10.1007/s00592-017-1023-9

88. Pai L-W, Li T-C, Hwu Y-J et al (2016) The effectiveness of regular leisure-time physical activities on long-term glycemic control in people with type 2 diabetes: a systematic review and meta-analysis. Diabetes Res Clin Pract 113:77-85. https://doi.org/10.1016/j. diabres.2016.01.011

89. Lee MS, Jun JH, Lim H-J, Lim H-S (2015) A systematic review and meta-analysis of tai chi for treating type 2 diabetes. Maturitas 80:14-23. https://doi.org/10.1016/j.maturitas.2014.09.008

90. Cui J, Yan J-H, Yan L-M et al (2017) Effects of yoga in adults with type 2 diabetes mellitus: a meta-analysis. J Diabetes Investig 8: 201-209. https://doi.org/10.1111/jdi.12548

91. Qiu S, Cai X, Chen X et al (2014) Step counter use in type 2 diabetes: a meta-analysis of randomized controlled trials. BMC Med 12:36. https://doi.org/10.1186/1741-7015-12-36

92. Franz MJ, Boucher JL, Rutten-Ramos S, VanWormer JJ (2015) Lifestyle weight-loss intervention outcomes in overweight and obese adults with type 2 diabetes: a systematic review and metaanalysis of randomized clinical trials. J Acad Nutr Diet 115:14471463. https://doi.org/10.1016/j.jand.2015.02.031

93. Aggarwal N, Singla A, Mathieu C et al (2018) Metformin extended-release versus immediate-release: an international, randomized, double-blind, head-to-head trial in pharmacotherapynaïve patients with type 2 diabetes. Diabetes Obes Metab 20: 463-467. https://doi.org/10.1111/dom.13104

94. Garber AJ, Duncan TG, Goodman AM et al (1997) Efficacy of metformin in type II diabetes: results of a double-blind, placebocontrolled, dose-response trial. Am J Med 103:491-497

95. Inzucchi SE, Lipska KJ, Mayo H et al (2014) Metformin in patients with type 2 diabetes and kidney disease: a systematic review. JAMA 312:2668-2675. https://doi.org/10.1001/jama.2014.15298

96. Lalau J-D, Kajbaf F, Bennis Y et al (2018) Metformin treatment in patients with type 2 diabetes and chronic kidney disease stages
3A, 3B, or 4. Diabetes Care 41:547-553. https://doi.org/10.2337/ dc17-2231

97. Imam TH (2017) Changes in metformin use in chronic kidney disease. Clin Kidney J 10:301-304. https://doi.org/10.1093/ckj/ sfx017

98. UK Prospective Diabetes Study (UKPDS) Group (1998) Effect of intensive blood-glucose control with metformin on complications in overweight patients with type 2 diabetes (UKPDS 34). Lancet 352:854-865

99. Griffin SJ, Leaver JK, Irving GJ (2017) Impact of metformin on cardiovascular disease: a meta-analysis of randomised trials among people with type 2 diabetes. Diabetologia 60:1620-1629. https://doi.org/10.1007/s00125-017-4337-9

100. Maruthur NM, Tseng E, Hutfless S et al (2016) Diabetes medications as monotherapy or metformin-based combination therapy for type 2 diabetes: a systematic review and meta-analysis. Ann Intern Med 164:740-751. https://doi.org/10.7326/M15-2650

101. Aroda VR, Edelstein SL, Goldberg RB et al (2016) Long-term metformin use and vitamin B12 deficiency in the Diabetes Prevention Program Outcomes Study. J Clin Endocrinol Metab 101:1754-1761. https://doi.org/10.1210/jc.2015-3754

102. Zhang X-L, Zhu Q-Q, Chen Y-H et al (2018) Cardiovascular safety, long-term noncardiovascular safety, and efficacy of sodiumglucose cotransporter 2 inhibitors in patients with type 2 diabetes mellitus: a systemic review and meta-analysis with trial sequential analysis. J Am Heart Assoc 7:e007165. https://doi.org/10.1161/ JAHA.117.007165

103. Storgaard H, Gluud LL, Bennett C et al (2016) Benefits and harms of sodium-glucose co-transporter 2 inhibitors in patients with type 2 diabetes: a systematic review and meta-analysis. PLoS One 11: e0166125. https://doi.org/10.1371/journal.pone.0166125

104. Li D, Wang T, Shen S et al (2017) Urinary tract and genital infections in patients with type 2 diabetes treated with sodium-glucose co-transporter 2 inhibitors: a meta-analysis of randomized controlled trials. Diabetes Obes Metab 19:348-355. https://doi.org/ 10.1111/dom. 12825

105. Jabbour S, Seufert J, Scheen A et al (2018) Dapagliflozin in patients with type 2 diabetes mellitus: a pooled analysis of safety data from phase IIb/III clinical trials. Diabetes Obes Metab 20:620 628. https://doi.org/10.1111/dom.13124

106. Tang H, Li D, Wang $\mathrm{T}$ et al (2016) Effect of sodium-glucose cotransporter 2 inhibitors on diabetic ketoacidosis among patients with type 2 diabetes: a meta-analysis of randomized controlled trials. Diabetes Care 39:e123-e124. https://doi.org/10.2337/ dc16-0885

107. Thrasher J (2017) Pharmacologic management of type 2 diabetes mellitus: available therapies. Am J Med 130:S4-S17. https://doi. org/10.1016/j.amjmed.2017.04.004

108. Karagiannis T, Liakos A, Bekiari E et al (2015) Efficacy and safety of once-weekly glucagon-like peptide 1 receptor agonists for the management of type 2 diabetes: a systematic review and metaanalysis of randomized controlled trials. Diabetes Obes Metab 17:1065-1074. https://doi.org/10.1111/dom.12541

109. Zaccardi F, Htike ZZ, Webb DR et al (2016) Benefits and harms of once-weekly glucagon-like peptide-1 receptor agonist treatments: a systematic review and network meta-analysis. Ann Intern Med 164:102-113. https://doi.org/10.7326/M15-1432

110. Htike ZZ, Zaccardi F, Papamargaritis D et al (2017) Efficacy and safety of glucagon-like peptide- 1 receptor agonists in type 2 diabetes: a systematic review and mixed-treatment comparison analysis. Diabetes Obes Metab 19:524-536. https://doi.org/10.1111/ dom. 12849

111. Sorli C, Harashima S-I, Tsoukas GM et al (2017) Efficacy and safety of once-weekly semaglutide monotherapy versus placebo in patients with type 2 diabetes (SUSTAIN 1): a double-blind, randomised, placebo-controlled, parallel-group, multinational, 
multicentre phase 3a trial. Lancet Diabetes Endocrinol 5:251-260. https://doi.org/10.1016/S2213-8587(17)30013-X

112. Pratley RE, Aroda VR, Lingvay I et al (2018) Semaglutide versus dulaglutide once weekly in patients with type 2 diabetes (SUSTAIN 7): a randomised, open-label, phase 3b trial. Lancet Diabetes Endocrinol 6:275-286. https://doi.org/10.1016/S22138587(18)30024-X

113. Dungan KM, Povedano ST, Forst T et al (2014) Once-weekly dulaglutide versus once-daily liraglutide in metformin-treated patients with type 2 diabetes (AWARD-6): a randomised, open-label, phase 3, non-inferiority trial. Lancet 384:1349-1357. https://doi. org/10.1016/S0140-6736(14)60976-4

114. Buse JB, Nauck M, Forst T et al (2013) Exenatide once weekly versus liraglutide once daily in patients with type 2 diabetes (DURATION-6): a randomised, open-label study. Lancet 381: 117-124. https://doi.org/10.1016/S0140-6736(12)61267-7

115. Buse JB, Rosenstock J, Sesti G et al (2009) Liraglutide once a day versus exenatide twice a day for type 2 diabetes: a 26 -week randomised, parallel-group, multinational, open-label trial (LEAD-6). Lancet 374:39-47. https://doi.org/10.1016/S01406736(09)60659-0

116. Drucker DJ, Buse JB, Taylor K et al (2008) Exenatide once weekly versus twice daily for the treatment of type 2 diabetes: a randomised, open-label, non-inferiority study. Lancet 372:1240 1250. https://doi.org/10.1016/S0140-6736(08)61206-4

117. Andreadis P, Karagiannis T, Malandris K et al (2018) Semaglutide for type 2 diabetes mellitus: a systematic review and meta-analysis. Diabetes Obes Metab 20:2255-2263. https://doi.org/10.1111/ dom.13361

118. Li Z, Zhang Y, Quan X et al (2016) Efficacy and acceptability of glycemic control of glucagon-like peptide-1 receptor agonists among type 2 diabetes: a systematic review and network metaanalysis. PLoS One 11:e154206. https://doi.org/10.1371/ journal.pone. 0154206

119. Storgaard H, Cold F, Gluud LL et al (2017) Glucagon-like peptide1 receptor agonists and risk of acute pancreatitis in patients with type 2 diabetes. Diabetes Obes Metab 19:906-908. https://doi.org/ 10.1111/dom.12885

120. Monami M, Nreu B, Scatena A et al (2017) Safety issues with glucagon-like peptide-1 receptor agonists (pancreatitis, pancreatic cancer and cholelithiasis): data from randomized controlled trials. Diabetes Obes Metab 19:1233-1241. https://doi.org/10.1111/ dom. 12926

121. Esposito K, Chiodini P, Maiorino MI et al (2014) Glycaemic durability with dipeptidyl peptidase- 4 inhibitors in type 2 diabetes: a systematic review and meta-analysis of long-term randomised controlled trials. BMJ Open 4:e005442. https://doi.org/10.1136/ bmjopen-2014-005442

122. Aroda VR, Henry RR, Han J et al (2012) Efficacy of GLP-1 receptor agonists and DPP-4 inhibitors: meta-analysis and systematic review. Clin Ther 34:1247-1258.e22. https://doi.org/10.1016/ j.clinthera.2012.04.013

123. Wu S, Chai S, Yang J et al (2017) Gastrointestinal adverse events of dipeptidyl peptidase 4 inhibitors in type 2 diabetes: a systematic review and network meta-analysis. Clin Ther 39:1780-1789.e33. https://doi.org/10.1016/j.clinthera.2017.07.036

124. Salvo F, Moore N, Arnaud M et al (2016) Addition of dipeptidyl peptidase-4 inhibitors to sulphonylureas and risk of hypoglycaemia: systematic review and meta-analysis. BMJ 353: i2231. https://doi.org/10.1136/bmj.i2231

125. Tkáć I, Raz I (2017) Combined analysis of three large interventional trials with gliptins indicates increased incidence of acute pancreatitis in patients with type 2 diabetes. Diabetes Care 40: 284-286. https://doi.org/10.2337/dc15-1707

126. Mascolo A, Rafaniello C, Sportiello L et al (2016) Dipeptidyl peptidase (DPP)-4 inhibitor-induced arthritis/arthralgia: a review of clinical cases. Drug Saf 39:401-407. https://doi.org/10.1007/ s40264-016-0399-8

127. Nauck MA, Meier JJ, Cavender MA et al (2017) Cardiovascular actions and clinical outcomes with glucagon-like peptide-1 receptor agonists and dipeptidyl peptidase-4 inhibitors. Circulation 136: 849-870. https://doi.org/10.1161/CIRCULATIONAHA.117. 028136

128. Li L, Li S, Deng K et al (2016) Dipeptidyl peptidase-4 inhibitors and risk of heart failure in type 2 diabetes: systematic review and meta-analysis of randomised and observational studies. BMJ 352: i610

129. Aronoff S, Rosenblatt S, Braithwaite S et al (2000) Pioglitazone hydrochloride monotherapy improves glycemic control in the treatment of patients with type 2 diabetes: a 6-month randomized placebo-controlled dose-response study. The Pioglitazone 001 Study Group. Diabetes Care 23:1605-1611

130. Einhorn D, Rendell M, Rosenzweig J et al (2000) Pioglitazone hydrochloride in combination with metformin in the treatment of type 2 diabetes mellitus: a randomized, placebo-controlled study. The Pioglitazone 027 Study Group. Clin Ther 22:1395-1409

131. Yki-Järvinen H (2004) Thiazolidinediones. N Engl J Med 351: 1106-1118. https://doi.org/10.1056/NEJMra041001

132. Kernan WN, Viscoli CM, Furie KL et al (2016) Pioglitazone after ischemic stroke or transient ischemic attack. N Engl J Med 374: 1321-1331. https://doi.org/10.1056/NEJMoa1506930

133. Hanefeld M, Marx N, Pfützner A et al (2007) Anti-inflammatory effects of pioglitazone and/or simvastatin in high cardiovascular risk patients with elevated high sensitivity C-reactive protein: the PIOSTAT Study. J Am Coll Cardiol 49:290-297. https://doi.org/ 10.1016/j.jacc.2006.08.054

134. Saremi A, Schwenke DC, Buchanan TA et al (2013) Pioglitazone slows progression of atherosclerosis in prediabetes independent of changes in cardiovascular risk factors. Arterioscler Thromb Vasc Biol 33:393-399. https://doi.org/10.1161/ATVBAHA.112. 300346

135. Nissen SE, Nicholls SJ, Wolski K et al (2008) Comparison of pioglitazone vs glimepiride on progression of coronary atherosclerosis in patients with type 2 diabetes: the PERISCOPE randomized controlled trial. JAMA 299:1561-1573. https://doi.org/10. 1001/jama.299.13.1561

136. Dormandy JA, Charbonnel B, Eckland DJA et al (2005) Secondary prevention of macrovascular events in patients with type 2 diabetes in the PROactive Study (PROspective pioglitAzone Clinical Trial In macroVascular Events): a randomised controlled trial. Lancet 366:1279-1289. https://doi. org/10.1016/S0140-6736(05)67528-9

137. Bach RG, Brooks MM, Lombardero M et al (2013) Rosiglitazone and outcomes for patients with diabetes mellitus and coronary artery disease in the Bypass Angioplasty Revascularization Investigation 2 Diabetes (BARI 2D) trial. Circulation 128:785794. https://doi.org/10.1161/CIRCULATIONAHA.112.000678

138. Mahaffey KW, Hafley G, Dickerson S et al (2013) Results of a reevaluation of cardiovascular outcomes in the RECORD trial. Am Heart J 166:240-249.e1. https://doi.org/10.1016/j.ahj.2013. 05.004

139. Cusi K, Orsak B, Bril F et al (2016) Long-term pioglitazone treatment for patients with nonalcoholic steatohepatitis and prediabetes or type 2 diabetes mellitus: a randomized trial. Ann Intern Med 165:305-315. https://doi.org/10.7326/M15-1774

140. Kahn SE, Haffner SM, Heise MA et al (2006) Glycemic durability of rosiglitazone, metformin, or glyburide monotherapy. N Engl J Med 355:2427-2443. https://doi.org/10.1056/NEJMoa066224

141. Home PD, Pocock SJ, Beck-Nielsen H et al (2009) Rosiglitazone evaluated for cardiovascular outcomes in oral agent combination therapy for type 2 diabetes (RECORD): a multicentre, 
randomised, open-label trial. Lancet Lond Engl 373:2125-2135. https://doi.org/10.1016/S0140-6736(09)60953-3

142. Hanefeld M, Brunetti P, Schernthaner GH et al (2004) One-year glycemic control with a sulfonylurea plus pioglitazone versus a sulfonylurea plus metformin in patients with type 2 diabetes. Diabetes Care 27:141-147. https://doi.org/10.2337/diacare.27.1. 141

143. Viscoli CM, Inzucchi SE, Young LH et al (2017) Pioglitazone and risk for bone fracture: safety data from a randomized clinical trial. J Clin Endocrinol Metab 102:914-922. https://doi.org/10.1210/jc. 2016-3237

144. Kahn SE, Zinman B, Lachin JM et al (2008) Rosiglitazoneassociated fractures in type 2 diabetes: an analysis from a diabetes outcome progression trial (ADOPT). Diabetes Care 31:845-851. https://doi.org/10.2337/dc07-2270

145. Lewis JD, Habel LA, Quesenberry CP et al (2015) Pioglitazone use and risk of bladder cancer and other common cancers in persons with diabetes. JAMA 314:265-277. https://doi.org/10.1001/ jama.2015.7996

146. Hirst JA, Farmer AJ, Dyar A et al (2013) Estimating the effect of sulfonylurea on $\mathrm{HbA}_{1 \mathrm{c}}$ in diabetes: a systematic review and metaanalysis. Diabetologia 56:973-984. https://doi.org/10.1007/ s00125-013-2856-6

147. UK Prospective Diabetes Study (UKPDS) Group (1998) Intensive blood-glucose control with sulphonylureas or insulin compared with conventional treatment and risk of complications in patients with type 2 diabetes (UKPDS 33). Lancet 352:837-853

148. ADVANCE Collaborative Group, Patel A, MacMahon S et al (2008) Intensive blood glucose control and vascular outcomes in patients with type 2 diabetes. N Engl J Med 358:2560-2572. https://doi.org/10.1056/NEJMoa0802987

149. Monami M, Dicembrini I, Kundisova L et al (2014) A metaanalysis of the hypoglycaemic risk in randomized controlled trials with sulphonylureas in patients with type 2 diabetes. Diabetes Obes Metab 16:833-840. https://doi.org/10.1111/dom.12287

150. Del Prato S, Camisasca R, Wilson C, Fleck P (2014) Durability of the efficacy and safety of alogliptin compared with glipizide in type 2 diabetes mellitus: a 2-year study. Diabetes Obes Metab 16:1239-1246. https://doi.org/10.1111/dom.12377

151. Mishriky BM, Cummings DM, Tanenberg RJ (2015) The efficacy and safety of DPP4 inhibitors compared to sulfonylureas as addon therapy to metformin in patients with type 2 diabetes: a systematic review and meta-analysis. Diabetes Res Clin Pract 109: 378-388. https://doi.org/10.1016/j.diabres.2015.05.025

152. Khunti K, Chatterjee S, Gerstein HC et al (2018) Do sulphonylureas still have a place in clinical practice? Lancet Diabetes Endocrinol. https://doi.org/10.1016/S2213-8587(18) 30025-1

153. Gangji AS, Cukierman T, Gerstein HC et al (2007) A systematic review and meta-analysis of hypoglycemia and cardiovascular events: a comparison of glyburide with other secretagogues and with insulin. Diabetes Care 30:389-394. https://doi.org/10.2337/ dc06-1789

154. Chan SP, Colagiuri S (2015) Systematic review and meta-analysis of the efficacy and hypoglycemic safety of gliclazide versus other insulinotropic agents. Diabetes Res Clin Pract 110:75-81. https:// doi.org/10.1016/j.diabres.2015.07.002

155. Holman RR, Paul SK, Bethel MA et al (2008) 10-year follow-up of intensive glucose control in type 2 diabetes. N Engl J Med 359: 1577-1589. https://doi.org/10.1056/NEJMoa0806470

156. Erpeldinger S, Rehman MB, Berkhout C et al (2016) Efficacy and safety of insulin in type 2 diabetes: meta-analysis of randomised controlled trials. BMC Endocr Disord 16:39. https://doi.org/10. 1186/s12902-016-0120-z

157. Owens DR, Traylor L, Mullins P, Landgraf W (2017) Patient-level meta-analysis of efficacy and hypoglycaemia in people with type 2 diabetes initiating insulin glargine $100 \mathrm{U} / \mathrm{mL}$ or neutral protamine Hagedorn insulin analysed according to concomitant oral antidiabetes therapy. Diabetes Res Clin Pract 124:57-65. https:// doi.org/10.1016/j.diabres.2016.10.022

158. Goldman J, Kapitza C, Pettus J, Heise T (2017) Understanding how pharmacokinetic and pharmacodynamic differences of basal analog insulins influence clinical practice. Curr Med Res Opin 33: 1821-1831. https://doi.org/10.1080/03007995.2017.1335192

159. Freemantle N, Chou E, Frois C et al (2016) Safety and efficacy of insulin glargine $300 \mathrm{u} / \mathrm{mL}$ compared with other basal insulin therapies in patients with type 2 diabetes mellitus: a network metaanalysis. BMJ Open 6:e009421. https://doi.org/10.1136/bmjopen2015-009421

160. Russell-Jones D, Gall M-A, Niemeyer M et al (2015) Insulin degludec results in lower rates of nocturnal hypoglycaemia and fasting plasma glucose vs. insulin glargine: a meta-analysis of seven clinical trials. Nutr Metab Cardiovasc Dis 25:898-905. https://doi.org/10.1016/j.numecd.2015.06.005

161. Lipska KJ, Parker MM, Moffet HH et al (2018) Association of initiation of basal insulin analogs vs neutral protamine hagedorn insulin with hypoglycemia-related emergency department visits or hospital admissions and with glycemic control in patients with type 2 diabetes. JAMA 320:53-62. https://doi.org/10.1001/jama. 2018.7993

162. Marso SP, McGuire DK, Zinman B et al (2017) Efficacy and safety of degludec versus glargine in type 2 diabetes. N Engl J Med 377:723-732. https://doi.org/10.1056/NEJMoa1615692

163. Rosenstock J, Hollander P, Bhargava A et al (2015) Similar efficacy and safety of LY2963016 insulin glargine and insulin glargine (Lantus®) in patients with type 2 diabetes who were insulin-naïve or previously treated with insulin glargine: a randomized, double-blind controlled trial (the ELEMENT 2 study). Diabetes Obes Metab 17:734-741. https://doi.org/10.1111/dom. 12482

164. ORIGIN Trial Investigators, Gerstein HC, Bosch J et al (2012) Basal insulin and cardiovascular and other outcomes in dysglycemia. N Engl J Med 367:319-328. https://doi.org/10. 1056/NEJMoa1203858

165. Riddle MC, Yki-Järvinen H, Bolli GB et al (2015) One-year sustained glycaemic control and less hypoglycaemia with new insulin glargine $300 \mathrm{U} / \mathrm{ml}$ compared with $100 \mathrm{U} / \mathrm{ml}$ in people with type 2 diabetes using basal plus meal-time insulin: the EDITION 1 12-month randomized trial, including 6-month extension. Diabetes Obes Metab 17:835-842. https://doi.org/10.1111/dom. 12472

166. Yki-Järvinen H, Bergenstal R, Ziemen M et al (2014) New insulin glargine 300 units $/ \mathrm{mL}$ versus glargine 100 units $/ \mathrm{mL}$ in people with type 2 diabetes using oral agents and basal insulin: glucose control and hypoglycemia in a 6-month randomized controlled trial (EDITION 2). Diabetes Care 37:3235-3243. https://doi.org/10. 2337/dc14-0990

167. Riddle MC, Bolli GB, Ziemen M et al (2014) New insulin glargine 300 units $/ \mathrm{mL}$ versus glargine 100 units $/ \mathrm{mL}$ in people with type 2 diabetes using basal and mealtime insulin: glucose control and hypoglycemia in a 6-month randomized controlled trial (EDITION 1). Diabetes Care 37:2755-2762. https://doi.org/10. 2337/dc14-0991

168. Khunti K, Damci T, Husemoen LL et al (2017) Exploring the characteristics of suboptimally controlled patients after 24 weeks of basal insulin treatment: an individualized approach to intensification. Diabetes Res Clin Pract 123:209-217. https://doi.org/10. 1016/j.diabres.2016.11.028

169. Jensen MD, Ryan DH, Apovian CM et al (2014) 2013 AHA/ ACC/TOS guideline for the management of overweight and obesity in adults: a report of the American College of Cardiology/ American Heart Association Task Force on practice guidelines 
and The Obesity Society. J Am Coll Cardiol 63:2985-3023. https://doi.org/10.1016/j.jacc.2013.11.004

170. Garvey WT, Mechanick JI, Brett EM et al (2016) American Association of Clinical Endocrinologists and American College of endocrinology comprehensive clinical practice guidelines for medical care of patients with obesity. Endocr Pract 22(Suppl 3):1203. https://doi.org/10.4158/EP161365.GL

171. Apovian CM, Aronne LJ, Bessesen DH et al (2015) Pharmacological management of obesity: an Endocrine Society clinical practice guideline. J Clin Endocrinol Metab 100:342362. https://doi.org/10.1210/jc.2014-3415

172. Moyer VA, U.S. Preventive Services Task Force (2012) Screening for and management of obesity in adults: U.S. Preventive Services Task Force recommendation statement. Ann Intern Med 157:373378. https://doi.org/10.7326/0003-4819-157-5-201209040-00475

173. Gaal LV, Dirinck E (2016) Pharmacological approaches in the treatment and maintenance of weight loss. Diabetes Care 39: S260-S267. https://doi.org/10.2337/dcS15-3016

174. Khera R, Pandey A, Chandar AK et al (2018) Effects of weightloss medications on cardiometabolic risk profiles: a systematic review and network meta-analysis. Gastroenterology 154:1309 1319.e7. https://doi.org/10.1053/j.gastro.2017.12.024

175. Davies MJ, Bergenstal R, Bode B et al (2015) Efficacy of liraglutide for weight loss among patients with type 2 diabetes: the SCALE diabetes randomized clinical trial. JAMA 314:687699. https://doi.org/10.1001/jama.2015.9676

176. Schauer PR, Bhatt DL, Kirwan JP et al (2014) Bariatric surgery versus intensive medical therapy for diabetes - 3-year outcomes. N Engl J Med 370:2002-2013. https://doi.org/10.1056/ NEJMoa1401329

177. Schauer PR, Bhatt DL, Kirwan JP et al (2017) Bariatric surgery versus intensive medical therapy for diabetes-5-year outcomes. N Engl J Med 376:641-651. https://doi.org/10.1056/ NEJMoa1600869

178. Ikramuddin S, Korner J, Lee W-J et al (2018) Lifestyle intervention and medical management with vs without roux-en-y gastric bypass and control of hemoglobin A1c, LDL cholesterol, and systolic blood pressure at 5 years in the diabetes surgery study. JAMA 319:266-278. https://doi.org/10.1001/jama.2017.20813

179. Dixon JB, O'Brien PE, Playfair J et al (2008) Adjustable gastric banding and conventional therapy for type 2 diabetes: a randomized controlled trial. JAMA 299:316-323. https://doi.org/10.1001/ jama.299.3.316

180. Mingrone G, Panunzi S, De Gaetano A et al (2012) Bariatric surgery versus conventional medical therapy for type 2 diabetes. N Engl J Med 366:1577-1585. https://doi.org/10.1056/ NEJMoa1200111

181. Sjöström L, Peltonen M, Jacobson P et al (2014) Association of bariatric surgery with long-term remission of type 2 diabetes and with microvascular and macrovascular complications. JAMA 311: 2297-2304. https://doi.org/10.1001/jama.2014.5988

182. Mingrone G, Panunzi S, De Gaetano A et al (2015) Bariatricmetabolic surgery versus conventional medical treatment in obese patients with type 2 diabetes: 5 year follow-up of an open-label, single-centre, randomised controlled trial. Lancet 386:964-973. https://doi.org/10.1016/S0140-6736(15)00075-6

183. Rubino F, Nathan DM, Eckel RH et al (2016) Metabolic surgery in the treatment algorithm for type 2 diabetes: a joint statement by international diabetes organizations. Diabetes Care 39:861-877. https://doi.org/10.2337/dc16-0236

184. Maggard-Gibbons M, Maglione M, Livhits M et al (2013) Bariatric surgery for weight loss and glycemic control in nonmorbidly obese adults with diabetes: a systematic review. JAMA 309:2250-2261. https://doi.org/10.1001/jama.2013.4851
185. Mingrone G, Bornstein S, Le Roux CW (2018) Optimisation of follow-up after metabolic surgery. Lancet Diabetes Endocrinol 6: 487-499. https://doi.org/10.1016/S2213-8587(17)30434-5

186. Conason A, Teixeira J, Hsu C-H et al (2013) Substance use following bariatric weight loss surgery. JAMA Surg 148:145-150. https://doi.org/10.1001/2013.jamasurg.265

187. Dawes AJ, Maggard-Gibbons M, Maher AR et al (2016) Mental health conditions among patients seeking and undergoing bariatric surgery: a meta-analysis. JAMA 315:150-163. https://doi.org/10. 1001/jama.2015.18118

188. Mechanick JI, Kushner RF, Sugerman HJ, et al (2009) American Association of Clinical Endocrinologists, The Obesity Society, and American Society for Metabolic \& Bariatric Surgery medical guidelines for clinical practice for the perioperative nutritional, metabolic, and nonsurgical support of the bariatric surgery patient. Obesity (Silver Spring) 17 Suppl 1:S1-S70, v. https://doi.org/10. 1038/oby.2009.28

189. Mechanick JI, Youdim A, Jones DB et al (2013) Clinical practice guidelines for the perioperative nutritional, metabolic, and nonsurgical support of the bariatric surgery patient-2013 update: cosponsored by American Association of Clinical Endocrinologists, The Obesity Society, and American Society for Metabolic \& Bariatric Surgery. Obesity (Silver Spring) 21(Suppl 1):S1-S27. https://doi.org/10.1002/oby.20461

190. Phung OJ, Sobieraj DM, Engel SS, Rajpathak SN (2014) Early combination therapy for the treatment of type 2 diabetes mellitus: systematic review and meta-analysis. Diabetes Obes Metab 16: 410-417. https://doi.org/10.1111/dom.12233

191. Abdul-Ghani MA, Puckett C, Triplitt C et al (2015) Initial combination therapy with metformin, pioglitazone and exenatide is more effective than sequential add-on therapy in subjects with newonset diabetes. Results from the Efficacy and Durability of Initial Combination Therapy for type 2 diabetes (EDICT): a randomized trial. Diabetes Obes Metab 17:268-275. https://doi.org/10.1111/ dom. 12417

192. Vijayakumar TM, Jayram J, Meghana Cheekireddy V et al (2017) Safety, efficacy, and bioavailability of fixed-dose combinations in type 2 diabetes mellitus: a systematic updated review. Curr Ther Res Clin Exp 84:4-9. https://doi.org/10.1016/j.curtheres.2017.01. 005

193. Mearns ES, Saulsberry WJ, White CM et al (2015) Efficacy and safety of antihyperglycaemic drug regimens added to metformin and sulphonylurea therapy in type 2 diabetes: a network metaanalysis. Diabet Med 32:1530-1540. https://doi.org/10.1111/ dme. 12837

194. Henry RR, Murray AV, Marmolejo MH et al (2012) Dapagliflozin, metformin XR, or both: initial pharmacotherapy for type 2 diabetes, a randomised controlled trial. Int J Clin Pract 66:446-456. https://doi.org/10.1111/j.1742-1241.2012.02911.x

195. Buse JB, Peters A, Russell-Jones D et al (2015) Is insulin the most effective injectable antihyperglycaemic therapy? Diabetes Obes Metab 17:145-151. https://doi.org/10.1111/dom.12402

196. Vaccaro O, Masulli M, Nicolucci A et al (2017) Effects on the incidence of cardiovascular events of the addition of pioglitazone versus sulfonylureas in patients with type 2 diabetes inadequately controlled with metformin (TOSCA.IT): a randomised, multicentre trial. Lancet Diabetes Endocrinol 5:887-897. https:// doi.org/10.1016/S2213-8587(17)30317-0

197. Wang Z, Sun J, Han R et al (2018) Efficacy and safety of sodiumglucose cotransporter-2 inhibitors versus dipeptidyl peptidase- 4 inhibitors as monotherapy or add-on to metformin in patients with type 2 diabetes mellitus: a systematic review and meta-analysis. Diabetes Obes Metab 20:113-120. https://doi.org/10.1111/dom. 13047

198. Kawalec P, Mikrut A, Łopuch S (2014) The safety of dipeptidyl peptidase-4 (DPP-4) inhibitors or sodium-glucose cotransporter 2 
(SGLT-2) inhibitors added to metformin background therapy in patients with type 2 diabetes mellitus: a systematic review and meta-analysis. Diabetes Metab Res Rev 30:269-283

199. Leiter LA, Yoon K-H, Arias P et al (2015) Canagliflozin provides durable glycemic improvements and body weight reduction over 104 weeks versus glimepiride in patients with type 2 diabetes on metformin: a randomized, double-blind, phase 3 study. Diabetes Care 38:355-364. https://doi.org/10.2337/dc13-2762

200. Del Prato S, Nauck M, Durán-Garcia S et al (2015) Long-term glycaemic response and tolerability of dapagliflozin versus a sulphonylurea as add-on therapy to metformin in patients with type 2 diabetes: 4-year data. Diabetes Obes Metab 17:581-590. https://doi.org/10.1111/dom.12459

201. Ridderstråle M, Andersen KR, Zeller C et al (2014) Comparison of empagliflozin and glimepiride as add-on to metformin in patients with type 2 diabetes: a 104-week randomised, active-controlled, double-blind, phase 3 trial. Lancet Diabetes Endocrinol 2: 691-700. https://doi.org/10.1016/S2213-8587(14)70120-2

202. Zhang Y, Hong J, Chi J et al (2014) Head-to-head comparison of dipeptidyl peptidase-IV inhibitors and sulfonylureas - a metaanalysis from randomized clinical trials. Diabetes Metab Res Rev 30:241-256. https://doi.org/10.1002/dmrr.2482

203. Foroutan N, Muratov S, Levine M (2016) Safety and efficacy of dipeptidyl peptidase-4 inhibitors vs sulfonylurea in metforminbased combination therapy for type 2 diabetes mellitus: systematic review and meta-analysis. Clin Invest Med Med Clin Exp 39:E48E62

204. Chen K, Kang D, Yu M et al (2018) Direct head-to-head comparison of glycaemic durability of dipeptidyl peptidase-4 inhibitors and sulphonylureas in patients with type 2 diabetes mellitus: a meta-analysis of long-term randomized controlled trials. Diabetes Obes Metab 20:1029-1033. https://doi.org/10.1111/ dom. 13147

205. Zaccardi F, Dhalwani NN, Dales J et al (2018) Comparison of glucose-lowering agents after dual therapy failure in type 2 diabetes: a systematic review and network meta-analysis of randomized controlled trials. Diabetes Obes Metab 20:985-997. https://doi. org/10.1111/dom. 13185

206. Downes MJ, Bettington EK, Gunton JE, Turkstra E (2015) Triple therapy in type 2 diabetes; a systematic review and network metaanalysis. PeerJ 3:e1461. https://doi.org/10.7717/peerj.1461

207. Lee CMY, Woodward M, Colagiuri S (2016) Triple therapy combinations for the treatment of type 2 diabetes - a network metaanalysis. Diabetes Res Clin Pract 116:149-158. https://doi.org/10. 1016/j.diabres.2016.04.037

208. Lukashevich V, Del Prato S, Araga M, Kothny W (2014) Efficacy and safety of vildagliptin in patients with type 2 diabetes mellitus inadequately controlled with dual combination of metformin and sulphonylurea. Diabetes Obes Metab 16:403-409. https://doi.org/ 10.1111/dom. 12229

209. Hong AR, Lee J, Ku EJ et al (2015) Comparison of vildagliptin as an add-on therapy and sulfonylurea dose-increasing therapy in patients with inadequately controlled type 2 diabetes using metformin and sulfonylurea (VISUAL study): a randomized trial. Diabetes Res Clin Pract 109:141-148. https://doi.org/10.1016/j. diabres.2015.04.019

210. Moses RG, Kalra S, Brook D et al (2014) A randomized controlled trial of the efficacy and safety of saxagliptin as add-on therapy in patients with type 2 diabetes and inadequate glycaemic control on metformin plus a sulphonylurea. Diabetes Obes Metab 16:443-450. https://doi.org/10.1111/dom.12234

211. Moses RG, Round E, Shentu Y et al (2016) A randomized clinical trial evaluating the safety and efficacy of sitagliptin added to the combination of sulfonylurea and metformin in patients with type 2 diabetes mellitus and inadequate glycemic control. J Diabetes 8: 701-711. https://doi.org/10.1111/1753-0407.12351
212. Singh S, Wright EE, Kwan AYM et al (2017) Glucagon-like peptide-1 receptor agonists compared with basal insulins for the treatment of type 2 diabetes mellitus: a systematic review and metaanalysis. Diabetes Obes Metab 19:228-238. https://doi.org/10. 1111/dom.12805

213. Levin PA, Nguyen H, Wittbrodt ET, Kim SC (2017) Glucagonlike peptide-1 receptor agonists: a systematic review of comparative effectiveness research. Diabetes Metab Syndr Obes Targets Ther 10:123-139. https://doi.org/10.2147/DMSO.S130834

214. Abd El Aziz MS, Kahle M, Meier JJ, Nauck MA (2017) A metaanalysis comparing clinical effects of short- or long-acting GLP-1 receptor agonists versus insulin treatment from head-to-head studies in type 2 diabetic patients. Diabetes Obes Metab 19:216-227. https://doi.org/10.1111/dom.12804

215. Eng C, Kramer CK, Zinman B, Retnakaran R (2014) Glucagonlike peptide-1 receptor agonist and basal insulin combination treatment for the management of type 2 diabetes: a systematic review and meta-analysis. Lancet 384:2228-2234. https://doi.org/10. 1016/S0140-6736(14)61335-0

216. Aroda VR, Bailey TS, Cariou B et al (2016) Effect of adding insulin degludec to treatment in patients with type 2 diabetes inadequately controlled with metformin and liraglutide: a doubleblind randomized controlled trial (BEGIN: ADD TO GLP-1 Study). Diabetes Obes Metab 18:663-670. https://doi.org/10. 1111/dom.12661

217. Aschner P, Sethi B, Gomez-Peralta F et al (2015) Insulin glargine compared with premixed insulin for management of insulin-naïve type 2 diabetes patients uncontrolled on oral antidiabetic drugs: the open-label, randomized GALAPAGOS study. J Diabetes Complicat 29:838-845. https://doi.org/10.1016/j.jdiacomp.2015. 04.003

218. Rosenstock J, Fonseca V, Schinzel S et al (2014) Reduced risk of hypoglycemia with once-daily glargine versus twice-daily NPH and number needed to harm with NPH to demonstrate the risk of one additional hypoglycemic event in type 2 diabetes: evidence from a long-term controlled trial. J Diabetes Complicat 28:742749. https://doi.org/10.1016/j.jdiacomp.2014.04.003

219. Tang H, Cui W, Li D et al (2017) Sodium-glucose co-transporter 2 inhibitors in addition to insulin therapy for management of type 2 diabetes mellitus: a meta-analysis of randomized controlled trials. Diabetes Obes Metab 19:142-147. https://doi.org/10.1111/dom. 12785

220. Rosenstock J, Jelaska A, Zeller C et al (2015) Impact of empagliflozin added on to basal insulin in type 2 diabetes inadequately controlled on basal insulin: a 78-week randomized, double-blind, placebo-controlled trial. Diabetes Obes Metab 17:936948. https://doi.org/10.1111/dom.12503

221. Rosenstock J, Jelaska A, Frappin G et al (2014) Improved glucose control with weight loss, lower insulin doses, and no increased hypoglycemia with empagliflozin added to titrated multiple daily injections of insulin in obese inadequately controlled type 2 diabetes. Diabetes Care 37:1815-1823. https://doi.org/10.2337/dc133055

222. Yang W, Cai X, Gao X et al (2017) Addition of dipeptidyl peptidase-4 inhibitors to insulin treatment in type 2 diabetes patients: a meta-analysis. J Diabetes Investig 9:813-821. https://doi. org/10.1111/jdi.12764

223. Min SH, Yoon J-H, Hahn S, Cho YM (2017) Comparison between SGLT2 inhibitors and DPP4 inhibitors added to insulin therapy in type 2 diabetes: a systematic review with indirect comparison meta-analysis: SGLT2 or DPP4 inhibitor with insulin. Diabetes Metab Res Rev 33:e2818. https://doi.org/10.1002/dmrr.2818

224. Wysham CH, Lin J, Kuritzky L (2017) Safety and efficacy of a glucagon-like peptide-1 receptor agonist added to basal insulin therapy versus basal insulin with or without a rapid-acting insulin in patients with type 2 diabetes: results of a meta-analysis. 
Postgrad Med 129:436-445. https://doi.org/10.1080/00325481. 2017.1297669

225. Maiorino MI, Chiodini P, Bellastella G et al (2017) Insulin and glucagon-like peptide 1 receptor agonist combination therapy in type 2 diabetes: a systematic review and meta-analysis of randomized controlled trials. Diabetes Care 40:614-624. https://doi.org/ $10.2337 / \mathrm{dc} 16-1957$

226. Gough SCL, Bode BW, Woo VC et al (2015) One-year efficacy and safety of a fixed combination of insulin degludec and liraglutide in patients with type 2 diabetes: results of a 26-week extension to a 26-week main trial. Diabetes Obes Metab 17:965973. https://doi.org/10.1111/dom.12498

227. Rosenstock J, Aronson R, Grunberger G et al (2016) Benefits of LixiLan, a titratable fixed-ratio combination of insulin glargine plus lixisenatide, versus insulin glargine and lixisenatide monocomponents in type 2 diabetes inadequately controlled on oral agents: the LixiLan-O randomized trial. Diabetes Care 39: 2026-2035. https://doi.org/10.2337/dc16-0917

228. Aroda VR, Rosenstock J, Wysham C et al (2016) Efficacy and safety of LixiLan, a titratable fixed-ratio combination of insulin glargine plus lixisenatide in type 2 diabetes inadequately controlled on basal insulin and metformin: the LixiLan-L randomized trial. Diabetes Care 39:1972-1980. https://doi.org/10.2337/dc161495

229. Garber AJ, Wahlen J, Wahl T et al (2006) Attainment of glycaemic goals in type 2 diabetes with once-, twice-, or thrice-daily dosing with biphasic insulin aspart 70/30 (the 12-3 study). Diabetes Obes Metab 8:58-66. https://doi.org/10. 1111/j.1463-1326.2005.00563.x

230. Linjawi S, Lee B-W, Tabak Ö et al (2018) A 32-week randomized comparison of stepwise insulin intensification of biphasic insulin aspart (BIAsp 30) versus basal-bolus therapy in insulin-naïve patients with type 2 diabetes. Diabetes Ther 9:1-11. https://doi.org/ 10.1007/s13300-017-0334-8

231. Raccah D, Huet D, Dib A et al (2017) Review of basal-plus insulin regimen options for simpler insulin intensification in people with type 2 diabetes mellitus. Diabet Med J Br Diabet Assoc 34:11931204. https://doi.org/10.1111/dme.13390

232. Rodbard HW, Visco VE, Andersen H et al (2014) Treatment intensification with stepwise addition of prandial insulin aspart boluses compared with full basal-bolus therapy (FullSTEP Study): a randomised, treat-to-target clinical trial. Lancet Diabetes Endocrinol 2:30-37. https://doi.org/10.1016/S22138587(13)70090-1

233. Giugliano D, Chiodini P, Maiorino MI et al (2016) Intensification of insulin therapy with basal-bolus or premixed insulin regimens in type 2 diabetes: a systematic review and meta-analysis of randomized controlled trials. Endocrine 51:417-428. https://doi.org/ 10.1007/s12020-015-0718-3

234. Wang C, Mamza J, Idris I (2015) Biphasic vs basal bolus insulin regimen in type 2 diabetes: a systematic review and meta-analysis of randomized controlled trials. Diabet Med 32:585-594. https:// doi.org/10.1111/dme.12694

235. Anyanwagu U, Mamza J, Gordon J et al (2017) Premixed vs basal-bolus insulin regimen in type 2 diabetes: comparison of clinical outcomes from randomized controlled trials and realworld data. Diabet Med 34:1728-1736. https://doi.org/10.1111/ dme. 13518

236. Aronson R, Reznik Y, Conget I et al (2016) Sustained efficacy of insulin pump therapy compared with multiple daily injections in type 2 diabetes: 12-month data from the OpT2mise randomized trial. Diabetes Obes Metab 18:500-507. https://doi.org/10.1111/ dom. 12642

237. Kelly S, Martin S, Kuhn I et al (2016) Barriers and facilitators to the uptake and maintenance of healthy behaviours by people at mid-life: a rapid systematic review. PLoS One 11:e0145074. https://doi.org/10.1371/journal.pone.0145074

238. Gee PM, Greenwood DA, Paterniti DA et al (2015) The eHealth enhanced chronic care model: a theory derivation approach. J Med Internet Res 17:e86. https://doi.org/10.2196/jmir.4067

239. Faruque LI, Wiebe N, Ehteshami-Afshar A et al (2017) Effect of telemedicine on glycated hemoglobin in diabetes: a systematic review and meta-analysis of randomized trials. CMAJ 189: E341-E364. https://doi.org/10.1503/cmaj.150885

240. Lee SWH, Chan CKY, Chua SS, Chaiyakunapruk N (2017) Comparative effectiveness of telemedicine strategies on type 2 diabetes management: a systematic review and network metaanalysis. Sci Rep 7:12680. https://doi.org/10.1038/s41598-017$12987-\mathrm{z}$

\section{Affiliations}

\section{Melanie J. Davies ${ }^{1,2}$. David A. D'Alessio ${ }^{3}$ - Judith Fradkin ${ }^{4}$ - Walter N. Kernan ${ }^{5}$. Chantal Mathieu ${ }^{6}$. Geltrude Mingrone ${ }^{7,8} \cdot$ Peter Rossing ${ }^{9,10} \cdot$ Apostolos Tsapas $^{11} \cdot$ Deborah J. Wexler $^{12,13} \cdot$ John B. Buse ${ }^{14}$}

1 Diabetes Research Centre, University of Leicester, Leicester, UK

2 Leicester Diabetes Centre, Leicester General Hospital, Leicester, LE5 4PW, UK

3 Department of Medicine, Duke University School of Medicine, Durham, NC, USA

4 National Institute of Diabetes and Digestive and Kidney Diseases, National Institutes of Health, Bethesda, MD, USA

5 Department of Medicine, Yale School of Medicine, New Haven, CT, USA

6 Clinical and Experimental Endocrinology, UZ Gasthuisberg, KU Leuven, Leuven, Belgium

7 Department of Internal Medicine, Catholic University, Rome, Italy
8 Diabetes and Nutritional Sciences, King's College London, London, UK

9 Steno Diabetes Center Copenhagen, Gentofte, Denmark

10 University of Copenhagen, Copenhagen, Denmark

11 Second Medical Department, Aristotle University Thessaloniki, Thessaloniki, Greece

12 Department of Medicine and Diabetes Unit, Massachusetts General Hospital, Boston, MA, USA

13 Harvard Medical School, Boston, MA, USA

14 Department of Medicine, University of North Carolina School of Medicine, Chapel Hill, NC, USA 